\title{
Thickness and multi-axial stress creep rupture criteria of the Type IV component of a ferritic steel weld
}

\author{
Document Version \\ Accepted author manuscript
}

Link to publication record in Manchester Research Explorer

\section{Citation for published version (APA):}

Hayhurst, R. J., Vakili-Tahami, F., Mustata, R., \& Hayhurst, D. (2004). Thickness and multi-axial stress creep rupture criteria of the Type IV component of a ferritic steel weld. 729-743.

\section{Citing this paper}

Please note that where the full-text provided on Manchester Research Explorer is the Author Accepted Manuscript or Proof version this may differ from the final Published version. If citing, it is advised that you check and use the publisher's definitive version.

\section{General rights}

Copyright and moral rights for the publications made accessible in the Research Explorer are retained by the authors and/or other copyright owners and it is a condition of accessing publications that users recognise and abide by the legal requirements associated with these rights.

\section{Takedown policy}

If you believe that this document breaches copyright please refer to the University of Manchester's Takedown Procedures [http://man.ac.uk/04Y6Bo] or contact uml.scholarlycommunications@manchester.ac.uk providing relevant details, so we can investigate your claim.

\section{OPEN ACCESS}




\title{
THICKNESS AND MULTI-AXIAL STRESS CREEP RUPTURE CRITERIA OF THE TYPE IV COMPONENT OF A FERRITIC STEEL WELD
}

\author{
by \\ R J Hayhurst, F Vakili-Tahami, R Mustata and D R Hayhurst* \\ *Corresponding Author
}

Department of Mechanical, Aerospace \& Manufacturing Engineering UMIST, PO Box 88, Manchester M60 1QD, UK. 


\begin{abstract}
The paper summarises previously derived constitutive parameters for the temperatures $575,590,600,620$ and $640^{\circ} \mathrm{C}$. Values of the multi-axial stress rupture parameter $v$ are reviewed and recorded. This constitutive parameter set is used to determine the thickness of the Type IV material zone to be $0.7 \mathrm{~mm}$. Next, values of Type IV multi-axial stress rupture parameter $v$ are determined for a wide range of butt-welded pipe and crosswelded uni-axial specimens, and an interpolation equation has been derived in terms of temperatures and stress level. Finally, CDM analyses have been performed for pipes and crosswelded testpieces, which include a CG-HAZ zone; and it has been shown that the constitutive parameter set, which corresponds to a minimum creep rate ratio of $1 / 2.5$, with respect to the parent material, gives accurate predictions of lifetimes and damage distributions.
\end{abstract}


Keywords: Creep, Continuum Damage Mechanics (CDM), Weldments, Finite Elements, Type IV, Coarse Grained Heat Affected Zone (CG-HAZ), Multi-axial Creep Rupture Criteria,

\section{NOTATION}

$\begin{array}{ll}\mathrm{S}_{\mathrm{ij}} & \text { Stress deviator } \\ \sigma & \text { Stress } \\ \sigma_{0} & \text { Normalising stress } \\ \sigma_{1} & \text { Maximum principle stress } \\ \sigma_{\mathrm{e}} & \text { Von Misses (effective) stress } \\ \sigma_{\mathrm{ij}} & \text { Stress Tensor } \\ \delta_{\mathrm{ij}} & \text { Kronecker Delta } \\ \varepsilon & \text { Strain } \\ \varepsilon_{\mathrm{e}} & \text { Effective strain } \\ \varepsilon_{\mathrm{f}} & \text { Stain at failure } \\ \varepsilon_{\mathrm{ij}}^{\mathrm{c}} & \text { Creep strain tensor } \\ \varepsilon_{\mathrm{ij}}^{\mathrm{e}} & \text { Elastic strain tensor } \\ \dot{\varepsilon}_{\mathrm{min}} & \text { Minimum strain rate } \\ \omega & \text { Creep constrained cavitation damage variable } \\ \omega_{\mathrm{f}} & \text { Rupture criterion } \\ \mathrm{H} & \text { Hardening variable } \\ \mathrm{N} & \text { Stress dependant step variable } \\ \Phi & \text { Carbide coarsening (ageing) variable } \\ \mathrm{A}, \mathrm{a}, \mathrm{B}, \mathrm{b}, \mathrm{C}, \mathrm{h}, \mathrm{H}^{*}, \mathrm{~K} \mathrm{c} & \text { Material constants } \\ \mathrm{C}_{\mathrm{ijkl}} & \text { Matrix of elastic constants } \\ \mathrm{T} & \text { Temperature }{ }^{\circ} \mathrm{K} \\ \theta & \text { Temperature }{ }^{\circ} \mathrm{C} \\ \alpha, v & \text { Multi-axial stress rupture parameters } \\ \mathrm{t}_{\mathrm{f}} & \text { Time to failure } \\ \lambda & \text { Lifetime prediction accuracy } \\ & \end{array}$

\section{Superscripts}

$\cdot$
Differentiation with respect to time Minimum cross-section stress

Elastic component

Creep component

Steady state value 


\subsection{INTRODUCTION}

Detailed systematic Continuum Damage Mechanics (CDM) analyses of ferritic steel weldments, carried out using DAMAGE XX, have been pioneered by Hall and Hayhurst (1991) and later developed by Wang and Hayhurst (1994). Hall and Hayhurst (1991) accurately predicted the deformation of a full-scale butt-welded pipe that had been tested by Coleman et al (1985). The CDM model included weld, HAZ, and parent material but neglected the presence of the Type IV zone at $565 \mathrm{PP}^{\circ} \mathrm{C}$. Fusion boundary failure was predicted to take place at the correct time in the weld material adjacent to the HAZ.

A similar approach has been adopted by Perrin and Hayhurst (1999) to analyse the creep deformation and rupture of weldments that are known to have failed in the Type IV material region. They showed how Finite Element CDM analysis techniques can be used to predict the results of experiments carried out on welded notched bars and uniaxial crosswelded testpieces at $640^{\circ} \mathrm{C}$. Both lifetime and deformation histories being well predicted.

Subsequently, research was carried out by Vakili-Tahami, Hayhurst and Wong (2003) on butt-welded pipes subjected to combined internal pressure and end load, at the temperatures of 590 and $620^{\circ} \mathrm{C}$. This research revealed two distinct failure mechanisms; firstly Type IV failure found under a predominance of end loading; and secondly, fusion boundary cracking encountered for low end loads. In the CDM predictions made by Vakili-Tahami, Hayhurst and Wang (2003) no directional cracking has been assigned to the damage parameter. This is because it is treated as a scalar variable; however, it may be postulated that micro-cracking may take place on planes perpendicular to the direction of principal strain. In this case Type IV cracking, under dominant axial loads, would be on planes perpendicular to the axis of the pipe; and fusion boundary cracking, under dominant internal pressure loadings, would involve short axial cracks. Although, the precise mechanism of micro-crack formation is a function of temperature, the ratio of internal pressure to axial loading, and the magnitude of the applied stress, these postulations are in line with anecdotal plant observations. The research revealed the importance of the multi-axial stress rupture criteria for all phases of weldment; and, of an accurate knowledge of the constitutive parameters.

Hayhurst and Miller (1994), using CDM, analysed a medium bore welded branch vessel under constant internal pressure using a 2-D axi-symmetric equivalent model. In their study constitutive equations were used, which had been extrapolated from $640^{\circ} \mathrm{C}$, using equations derived by Perrin and Hayhurst (1996) for the temperature range $600-675^{\circ} \mathrm{C}$.

The need was recognised by Hayhurst and Miller (1994) and by Vakili-Tahami, Hayhurst and Wong (2003) to establish a robust set of constitutive equations. Research has been carried out by Mustata et al (2003) which involves the use of such equations in 3-D Continuum Damage Mechanics analyses of ferritic steel (0.5Cr 0.5Mo $0.25 \mathrm{~V}$ ) welded 2.25Cr $1 \mathrm{Mo}$ branched pipes which have been tested at $590^{\circ} \mathrm{C}$.

The purpose of this paper is to state the deficiencies in the available constitutive equations, to seek to rectify them and to summarise best knowledge regarding welds prepared from $0.5 \mathrm{Cr} 0.5 \mathrm{Mo} 0.25 \mathrm{~V}$ parent material and $2.25 \mathrm{Cr} 1 \mathrm{Mo}$ weld material, with particular reference to the temperature of $590^{\circ} \mathrm{C}$, namely the test temperature of the medium bore branch, analysed in 2-D by Hayhurst and Miller (1994) and to be subsequently analysed in 3D by the present authors (Mustata, Hayhurst, Vakili-Tahami and Hayhurst, 2003) and (Hayhurst, Hayhurst and Vakili-Tahami, 2003).

The paper first presents the creep constitutive equations and summarises the constitutive parameters.

\subsection{CONSTITUTIVE EQUATIONS AND PARAMETERS}

CDM-based constitutive equations are used to describe the softening mechanisms, damage initiation and growth in low alloy $0.5 \mathrm{Cr} 0.5 \mathrm{Mo} 0.25 \mathrm{~V}$ steels. These 


\begin{tabular}{|c|c|c|c|c|c|}
\hline $575^{\circ} \mathrm{C}$ & Parent & Weld & Refined HAZ & Type IV & CG HAZ \\
\hline $\mathbf{A}\left(\mathrm{h}^{-1}\right)$ & $7.6959 \times 10^{-10}$ & $2.7444 \times 10^{-8}$ & $7.6959 \times 10^{-10}$ & $1.0285 \times 10^{-9}$ & $3.7850 \times 10^{-11}$ \\
\hline $\mathrm{B}\left(\mathrm{MPa}^{-1}\right)$ & $1.1405 \times 10^{-1}$ & $0.8464 \times 10^{-1}$ & $1.1405 \times 10^{-1}$ & $1.0905 \times 10^{-1}$ & $1.8640 \times 10^{-1}$ \\
\hline C (-) & 5.8171 & 5.4382 & 5.8171 & 9.4468 & 11.8800 \\
\hline h (MPa) & $3.3030 \times 10^{4}$ & $1.1353 \times 10^{4}$ & $3.3030 \times 10^{4}$ & $2.9812 \times 10^{4}$ & $3.8150 \times 10^{4}$ \\
\hline $\mathbf{H}^{*}(-)$ & 0.4390 & 0.3586 & 0.4390 & 0.5177 & 0.6186 \\
\hline $\mathrm{K}_{\mathrm{c}}\left(\mathrm{hPP}^{-1}\right)$ & $5.6686 \times 10^{-5}$ & $2.0026 \times 10^{-5}$ & $5.6686 \times 10^{-5}$ & $4.0840 \times 10^{-4}$ & $0.9375 \times 10^{-4}$ \\
\hline$v(-)$ & 2.8 & 3.0382 & 2.8 & 4.84 & 2.9191 \\
\hline
\end{tabular}

\begin{tabular}{|c|c|c|c|c|c|}
\hline $590^{\circ} \mathrm{C}$ & Parent & Weld & Refined HAZ & Type IV & CG HAZ \\
\hline$A\left(h^{-1}\right)$ & $1.3913 \times 10^{-9}$ & $2.8898 \times 10^{-8}$ & $1.3913 \times 10^{-9}$ & $5.2879 \times 10^{-9}$ & $1.5844 \times 10^{-10}$ \\
\hline $\mathbf{B}\left(\mathrm{MPa}^{-1}\right)$ & $1.4337 \times 10^{-1}$ & $1.1109 \times 10^{-1}$ & $1.4337 \times 10^{-1}$ & $1.1762 \times 10^{-1}$ & $1.9746 \times 10^{-1}$ \\
\hline C (-) & 2.9983 & 3.7894 & 2.9983 & 6.7693 & 8.8783 \\
\hline h (MPa) & $7.3288 \times 10^{4}$ & $2.4649 \times 10^{4}$ & $7.3288 \times 10^{4}$ & $2.9714 \times 10^{4}$ & $6.2785 \times 10^{4}$ \\
\hline $\mathbf{H}^{*}(-)$ & 0.4218 & 0.4088 & 0.4218 & 0.5430 & 0.6281 \\
\hline $\mathbf{K}_{\mathrm{c}}\left(\mathbf{h P P} \mathbf{P}^{-1}\right)$ & $1.0020 \times 10^{-4}$ & $5.2579 \times 10^{-5}$ & $1.002 \times 10^{-4}$ & $6.3709 \times 10^{-4}$ & $1.4047 \times 10^{-4}$ \\
\hline$v(-)$ & 2.8 & 2.7955 & 2.8 & 5.3106 & 2.7977 \\
\hline
\end{tabular}

\begin{tabular}{|c|c|c|c|c|c|}
\hline $600^{\circ} \mathrm{C}$ & Parent & Weld & Refined HAZ & Type IV & CG HAZ \\
\hline$A\left(\mathrm{MPa} \mathrm{h}^{-1}\right)$ & $2.6596 \times 10^{-9}$ & $2.9867 \times 10^{-8}$ & $2.6596 \times 10^{-9}$ & $1.5051 \times 10^{-8}$ & $7.2650 \times 10^{-10}$ \\
\hline $\mathbf{B}\left(\mathbf{M P a}^{-1}\right)$ & $1.5648 \times 10^{-1}$ & $1.3217 \times 10^{-1}$ & $1.5648 \times 10^{-1}$ & $1.2344 \times 10^{-1}$ & $2.1070 \times 10^{-1}$ \\
\hline C (-) & 3.0117 & 3.0084 & 3.0117 & 5.4710 & 7.4544 \\
\hline h (MPa) & $7.8024 \times 10^{4}$ & $4.0450 \times 10^{4}$ & $7.8024 \times 10^{4}$ & $2.9651 \times 10^{4}$ & $8.1590 \times 10^{4}$ \\
\hline $\mathbf{H}^{*}(-)$ & 0.4889 & 0.4445 & 0.4889 & 0.5598 & 0.6138 \\
\hline $\mathbf{K}_{\mathrm{c}}\left(\mathbf{h P P} \mathbf{P}^{-\mathbf{1}}\right)$ & $1.3615 \times 10^{-4}$ & $9.7421 \times 10^{-5}$ & $1.3615 \times 10^{-4}$ & $8.4640 \times 10^{-4}$ & $1.5140 \times 10^{-4}$ \\
\hline$v(-)$ & 2.8 & 2.6336 & 2.8 & 5.3762 & 2.7168 \\
\hline
\end{tabular}

\begin{tabular}{|c|c|c|c|c|c|}
\hline $620^{\circ} \mathrm{C}$ & Parent & Weld & Refined HAZ & Type IV & CG HAZ \\
\hline $\mathrm{A}\left(\mathrm{MPa}^{-1}\right)$ & $6.6741 \times 10^{-9}$ & $3.1803 \times 10^{-8}$ & $6.6741 \times 10^{-9}$ & $1.1021 \times 10^{-7}$ & $1.4676 \times 10^{-9}$ \\
\hline $\mathbf{B}\left(\mathbf{M P a}^{-1}\right)$ & $1.9786 \times 10^{-1}$ & $1.8397 \times 10^{-1}$ & $1.9786 \times 10^{-1}$ & $1.3533 \times 10^{-1}$ & $2.5080 \times 10^{-1}$ \\
\hline C (-) & 1.8479 & 1.9390 & 1.8479 & 3.6481 & 6.2210 \\
\hline h (MPa) & $1.4764 \times 10^{5}$ & $1.0384 \times 10^{5}$ & $1.4764 \times 10^{5}$ & $2.9533 \times 10^{4}$ & $1.4000 \times 10^{5}$ \\
\hline $\mathrm{H}^{*}(-)$ & 0.5295 & 0.5212 & 0.5295 & 0.5933 & 0.6225 \\
\hline $\mathbf{K}_{\mathrm{c}}\left(\mathbf{h P P} \mathbf{P}^{-1}\right)$ & $2.6084 \times 10^{-4}$ & $3.1507 \times 10^{-4}$ & $2.6084 \times 10^{-4}$ & $1.4534 \times 10^{-3}$ & $3.194 \times 10^{-4}$ \\
\hline$v(-)$ & 2.8 & 2.3100 & 2.8 & 4.9855 & 2.555 \\
\hline
\end{tabular}

\begin{tabular}{|c|c|c|c|c|c|}
\hline $640^{\circ} \mathrm{C}$ & Parent & Weld & Refined HAZ & Type IV & CG HAZ \\
\hline $\mathrm{A}\left(\mathrm{MPa} \mathrm{h}^{-1}\right)$ & $1.5812 \times 10^{-8}$ & $3.3731 \times 10^{-8}$ & $1.5812 \times 10^{-8}$ & $7.1251 \times 10^{-7}$ & $5.348 \times 10^{-9}$ \\
\hline $\mathbf{B}\left(\mathrm{MPa}^{-1}\right)$ & $2.4655 \times 10^{-1}$ & $2.5083 \times 10^{-1}$ & $2.4655 \times 10^{-1}$ & $1.4751 \times 10^{-1}$ & $3.359 \times 10^{-1}$ \\
\hline C (-) & 1.1690 & 1.2845 & 1.1690 & 2.4950 & 3.2020 \\
\hline h (MPa) & $2.6846 \times 10^{5}$ & $2.5129 \times 10^{5}$ & $2.6846 \times 10^{5}$ & $2.9422 \times 10^{4}$ & $2.8390 \times 10^{5}$ \\
\hline $\mathbf{H}^{*}(-)$ & $5.7066 \times 10^{-1}$ & $6.052 \times 10^{-1}$ & $5.7066 \times 10^{-1}$ & $6.2642 \times 10^{-1}$ & $7.0100 \times 10^{-1}$ \\
\hline$K_{c}\left(h P P^{-1}\right)$ & $4.7981 \times 10^{-4}$ & $9.4689 \times 10^{-4}$ & $4.7981 \times 10^{-4}$ & $2.4129 \times 10^{-3}$ & $5.070 \times 10^{-4}$ \\
\hline$v(-)$ & 2.8 & 1.9864 & 2.8 & 2.1326 & 2.3932 \\
\hline
\end{tabular}

Table 1: Ferritic steel constitutive parameters used in the cross-weld five material analysis for the temperatures $575,590,600,620$ and $640^{\circ} \mathrm{C}$ for the minimum crosssection average stress of $69.5 \mathrm{MPa}$. 
equations incorporate two damage state variables: firstly $\Phi$, which models the coarsening of carbide precipitates, is described by the physics of the process to vary from zero to unity. The coarsening of the carbide precipitates or 'ageing' leads to a progressive loss in the creep resistance of particle hardened alloys such as ferritic steels. The second state variable, $\omega$, represents the inter-granular creep constrained cavitation damage and is chosen to vary from zero for the virgin state to $\omega_{\mathrm{f}}$ at failure. A further hardening state variable, $\mathrm{H}$ is used to represent the strain hardening effect attributed to primary creep. Initially, $\mathrm{H}$ is zero and increases, as strain accumulates, to a limiting value $\mathrm{H}^{*}$ at steady-state creep. The uni-axial form of the constitutive equations for ferritic steels are given by the following set:

$$
\begin{gathered}
\dot{\varepsilon}=\mathrm{A} \sinh \left[\frac{\mathrm{B} \sigma(1-\mathrm{H})}{(1-\Phi)(1-\omega)}\right] \\
\dot{\mathrm{H}}=\frac{\mathrm{h} \dot{\varepsilon}}{\sigma}\left(1-\frac{\mathrm{H}}{\mathrm{H}^{*}}\right) \\
\dot{\Phi}=\frac{\mathrm{K}_{\mathrm{c}}}{3}(1-\Phi)^{4} \\
\dot{\omega}=\mathrm{C} \dot{\varepsilon}
\end{gathered}
$$

with the corresponding multi-axial form:

$$
\begin{gathered}
\dot{\varepsilon}_{\mathrm{ij}}=\frac{3}{2} \mathrm{~S}_{\mathrm{ij}} \mathrm{A} \sinh \left[\frac{\mathrm{B} \sigma_{\mathrm{e}}(1-\mathrm{H})}{(1-\Phi)(1-\omega)}\right] \\
\dot{\mathrm{H}}=\frac{\mathrm{h} \dot{\varepsilon}_{\mathrm{e}}}{\sigma_{\mathrm{e}}}\left(1-\frac{\mathrm{H}}{\mathrm{H}^{*}}\right) \\
\dot{\Phi}=\frac{\mathrm{K}_{\mathrm{c}}}{3}(1-\Phi)^{4} \\
\dot{\omega}=\mathrm{CN} \dot{\varepsilon}_{\mathrm{e}}\left(\frac{\sigma_{1}}{\sigma_{\mathrm{e}}}\right)^{\mathrm{v}}
\end{gathered}
$$

where $\mathrm{A}, \mathrm{B}, \mathrm{C}, \mathrm{h}, \mathrm{H}^{*}$ and $\mathrm{K}_{\mathrm{c}}$ are material constants to be determined after the data fitting. In the multi-axial form, $\mathrm{S}_{\mathrm{ij}}=\sigma_{\mathrm{ij}}-\delta_{\mathrm{ij}} \sigma_{\mathrm{kk}} / 3$ is the stress deviator, $\sigma_{\mathrm{e}}=\left(3 \mathrm{~S}_{\mathrm{ij}} \mathrm{S}_{\mathrm{ij}} / 2\right)^{-1 / 2}$ is the Von Misses stress and $\sigma_{1}$ is the maximum principal stress. $\mathrm{N}=1$ when $\sigma_{1}>0$ and $\mathrm{N}=0$ otherwise. The parameter $v$ is the multi-axial stress sensitivity index.

Constitutive parameters (A, B, C, h, $\mathrm{H}^{*}$ and $\mathrm{K}_{\mathrm{c}}$ ) derived by Mustata and Hayhurst (2001) and by Hayhurst, Mustata and Hayhurst (2003) are summarised in Table 1. The data at $575,600,620$ and $640 \mathrm{PP}^{\circ} \mathrm{C}$ will be used in this paper to analyse pipes and crosswelded structures. Data for $590^{\circ} \mathrm{C}$, the temperature of the medium bore branch test, Mustata et al (2003), is included for completeness. Values of the multi-axial stress rupture parameter are also given in Table 1. All constitutive parameters have been determined from the extrapolation formula (Hayhurst, Mustata and Hayhurst, 2003) with two exceptions: firstly, the parent parameters at $590^{\circ} \mathrm{C}$ have been determined by Mustata and Hayhurst (2001) from data collected on material from the same batch as the medium bore branch (Miller, 2000); and, secondly, the Coarse Grained HAZ parameters for $575^{\circ} \mathrm{C}, 600^{\circ} \mathrm{C}, 620^{\circ} \mathrm{C}$ and $640^{\circ} \mathrm{C}$ are point values, and those for $590^{\circ} \mathrm{C}$ have been determined using the extrapolation formula (Hayhurst, Mustata and Hayhurst, 2003).

In the next section the multi-axial stress rupture parameter $v$ is addressed. 


\subsection{MULTI-AXIAL STRESS RUPTURE PARAMETER $v$ : VALUES FOR ALL WELDMENT PHASES}

\subsection{First Estimates}

\section{(a) Behaviour of Parent, Weld and HAZ Materials at $565^{\circ} \mathrm{C}$}

There are only limited data in the literature quantifying the effect of stress state on cavity nucleation; early approaches are due to Dyson and McLean (1977). Similar ideas have been used by Cane (1981) to express the damage rate evolution equation in a form which may be integrated for both time and damage variables to yield the isochronous rupture locus in the normalised stress space $\sigma_{\mathrm{ij}} / \sigma_{0}$, where $\sigma_{0}$ is the uni-axial normalising stress.

Hall and Hayhurst (1991) have made the equivalence between Cane's formulation and the formulation of Hayhurst (1972) in terms of the $\alpha$ parameter he used to describe the isochronous rupture locus.

The two material phases for which no assumptions have been made are those tested by Cane (1981): Parent material and simulated HAZ (grain-coarsed HAZ) and the corresponding values for the multi-axial stress-rupture parameter $\alpha$ were $\alpha_{\text {PARENT }}=0.5955$ and $\alpha_{\text {HAZ }}=0.4298$.

With regard to the weld material, Hall and Hayhurst (1991) write: 'No data are available for the multi-axial rupture criterion for the weld metal and, in the absence of more precise data, it is assumed to be the same as that of the heat affected zone material $(\alpha=$ 0.4298), as the coarse- and fine-grain heat-affected zone and weld metal show some microstructural similarity in that they both have almost fully bainitic microstructures (Coleman 1988)'. Therefore, following Hall and Hayhurst (1991), is will be assumed that $\alpha_{\text {WELD }}=0.4298$.

The procedure adopted for mapping the $\alpha$ parameter into the $v$ parameter for this temperature consisted of:

(i) fitting of the creep data for the PARENT, HAZ and WELD metals to obtain the constitutive parameters;

(ii) to take account of the stress level dependency of the isochronous loci the multi-axial constitutive equations were integrated to produce the isochronous rupture locus for various stress levels;

(iii) for the two selected extreme uni-axial stress values of the tests performed, the corresponding $v$ values were determined by geometrical differencing of the isochronous rupture locus produced with the stress-independent $\alpha$ value; and

(iv) the average was the taken of the two extreme values of $v$.

This procedure was followed for each of the phases, namely parent, HAZ and weld, and the results are listed in Table 2.

\begin{tabular}{|c|c|c|c|c|c|c|}
\hline \multirow{2}{*}{ Phase } & \multirow{2}{*}{$\alpha$} & \multicolumn{2}{|c|}{ Stress MPa } & \multicolumn{3}{c|}{$\nu$} \\
\cline { 3 - 7 } & & Low & High & Low Stress & Mean & High Stress \\
\hline PARENT & 0.5955 & 85 & 110 & 4.85 & 4.715 & 4.58 \\
\hline HAZ & 0.4298 & 85 & 100 & 3.35 & 3.300 & 3.25 \\
\hline WELD & 0.4298 & 56 & 92 & 3.90 & 3.200 & 2.50 \\
\hline
\end{tabular}

Table 2: Values of $v$ for high and low stresses at $565^{\circ} \mathrm{C}$ determined by mapping $\alpha$ into $\nu$. 


\section{(b) Behaviour of Type IV Material at $640^{\circ} \mathrm{C}$}

As part of the experimental programme of Type IV failure Walker et al (1996) and Walker (1997) (Bristol data) have performed creep tests on a circumferentially notched bar made entirely of simulated Type IV material (homogeneous notched bar), and on notched bars made from welded material such that the Type IV material lies on the minimum cross section of the notch at the temperature of $640^{\circ} \mathrm{C}$. The deformation and rupture of these notched bars has been modelled by Perrin and Hayhurst (1999) using Finite Element Continuum Damage Mechanics (FECDM) techniques to determine a value for the multi-axial stress rupture criterion $v$ for the Type IV material. Perrin and Hayhurst (1999) inferred a value $\nu_{\text {TypeIV }}=2.8$, that ensures the computed lifetimes of the homogeneous and the welded notched bars are within $10 \%$ of the experimental lifetime.

\section{(c) Behaviour of Parent Material at $675^{\circ} \mathrm{C}$}

From the set of experimental multi-axial tests performed by Browne et al (1981) at $675^{\circ} \mathrm{C}$ on internally pressurised thick cylinders and circumferentially notched bars, Perrin and Hayhurst (1996) used the FECDM method to infer a value for the multi-axial stress state index $v$. The large deformation FECDM analyses produced a value $\nu_{\mathrm{PARENT}}=2.8$.

\section{(d) Determination of Multi-Axial Stress-Rupture Parameter $v$ for other Temperatures}

Values of the multi-axial stress-rupture parameter $v$ have been plotted in Figure 1 for the temperatures $565,640,675^{\circ} \mathrm{C}$. The linear trend for the multi-axial stress-rupture parameter for the parent material obtained from the values at $565^{\circ} \mathrm{C}$ and $675^{\circ} \mathrm{C}$ is highlighted, and trends for the other phases have been drawn parallel to the above determined line so that they incorporate the known values for $\mathrm{HAZ}$ and $\mathrm{WELD}$ at $565^{\circ} \mathrm{C}$ and for Type IV material at $640^{\circ} \mathrm{C}$.

\subsection{Revised Estimates}

Preliminary scoping studies have been carried out to ascertain the effectiveness of using the constitutive parameters due to Mustata and Hayhurst (2001) and the multi-axial stress rupture parameter values $v$ given in Figure 1. These have involved CDM calculations of damage evolution and failure times in crosswelded uni-axial testpieces (Perrin et al, 1999) and in welded medium bore branch connections (Hayhurst and Miller,1994; and Mustata et al, 2003). These investigations revealed that the $v$ values for the parent material given in Figure 1 were incorrect.

In further preliminary scoping studies the value of $v=4.715$ at $565^{\circ} \mathrm{C}$ was found to be too high; however, the value of $\nu=2.8$ at $675^{\circ} \mathrm{C}$, which derives from test data by Browne et al (1981) was assumed to hold across the temperature range $565-675^{\circ} \mathrm{C}$. Further CDM studies showed that for the three-dimensional structures considered, medium bore branch (Mustata et al, 2003) internally pressurised pipes and crosswelds (Hayhurst and Goodall, 2003), the approximation of $\nu=2.8$ for all temperatures is acceptable.

\begin{tabular}{|c|c|c|}
\hline \multicolumn{3}{|c|}{$\boldsymbol{v}=\mathbf{a}-\mathbf{b} \boldsymbol{\theta}$} \\
\hline Material Phase & $\mathbf{a}$ & $\mathbf{b}$ \\
\hline Parent & 2.8 & 0 \\
\hline R-HAZ & 2.8 & 0 \\
\hline CG-HAZ & 7.57138710 & 0.00809095 \\
\hline Weld & 12.34277422 & 0.01618190 \\
\hline
\end{tabular}

Table 3: Linear interpolation equation coefficients for multi-axial stress rupture parameter $\mathbf{n}$ with temperature $\theta^{\circ} \mathrm{C}$ 
For reasons of similarity in the microstructure, and following Hayhurst and Miller (1994) the refined HAZ (R-HAZ) was assumed to have the same value as the parent material. In the CDM analyses carried out for the further preliminary scoping studies the temperature variation of $v$ for the weld material was assumed to be that given in Figure 1.

Also, in the same preliminary scoping studies, assumptions had to be made for the $v$ values of the coarse-grained HAZ. This is a narrow region of material sandwiched between the weld and refined HAZ materials, and consequently it is difficult to test under multi-axial conditions. Further, it is only recently that its importance has been examined in crosswelds (Hayhurst, Vakili-Tahami and Hayhurst, 2003) and in medium-bore welded branch connections (Mustata et al, 2003). For the purpose of the CDM analyses the values of $v$ for the CG-HAZ were assumed to be the average of those for the two adjacent materials, i.e. the weld and the refined HAZ.

All values of $v$ used in these studies for the different weldment phases are summarised in Figure 2, and the coefficients in the equation

$$
\nu=\alpha-b \theta
$$

where $\theta$ is the temperature in ${ }^{\circ} \mathrm{C}$, are given in Table 3 .

So far, one material phase has not been considered, namely the Type IV material, which is sandwiched between the parent and refined HAZ. There are two questions to be answered: firstly, what is the effective thickness of the Type IV zone for use in CDM analyses; and, secondly what are the corresponding values of $v$, the multi-axial stress rupture parameter. These two issues are addressed in the following sections.

\subsection{DETERMINATION OF TYPE IV THICKNESS AND MULTI-AXIAL STRESS RUPTURE PARAMETER $v$}

To determine the thickness of the Type IV material zone for use in CDM analyses, and the value of the multi-axial stress rupture parameter $v$ for the Type IV region, use will be made of experimental data collected on two types of welded testpieces used by Gooch et al (1987) and Fairman (1995):

(i) internally pressurised pipes subjected to independent endloads; and

(ii) uni-axially loaded crosswelded testpieces.

The above tests were carried out on welds prepared from $0.5 \mathrm{Cr} 0.5 \mathrm{Mo} 0.25 \mathrm{~V}$ ferritic steel parent material and 2.25Cr lMo weld material. Both pipe and crosswelded testpieces were tested at 575, 600, 620 and $640^{\circ} \mathrm{C}$. To ensure that exactly the same weldments were creep tested in both the pipe and crossweld tests, two sections of parent material were butt-welded following the same procedures as those used in plant fabrication. From this component, pipes and uni-axial cross-weld testpieces were machined with the plane of the weld perpendicular to either the pipe axis, or to the axis of loading in the case of the cross-welded testpiece. In this way, both the thickness of the Type IV zone and its metallurgical state were uniformly controlled from specimen to specimen.

To understand, and to quantify, the interaction between Type IV thickness and the value of the multi-axial stress rupture parameter $v$ it was necessary to carry out a matrix of CDM analyses for different values of $v$ and Type IV thickness, t, which cover the expected domain of values. Then, from this database the values of $v$ and t were determined which:

accurately match the predicted and experimentally measured lifetimes; and 
(ii) provide evidence that the predicted fields of damage corroborate those obtained from metallographic examinations.

In this way CDM analyses have been carried out on the butt-welded pipes and crosswelded testpieces using the constitutive parameters of Table 1 and the values of $v$ given in Section 3 .

In the next section the CDM analysis techniques are addressed.

\subsection{CDM ANALYSES OF 2-D AXISYMMETRIC-PIPES AND PLANE STRAIN- CROSSWELDS}

Creep damage describes the material degradation which gives rise to the acceleration of creep rate known as tertiary creep. The damaged material is treated as a continuum. In a continuous body under load, the constitutive equations are used to describe how stress, strain rate and damage are interrelated at a point (or at an element) in the material. Different points in the body suffer different stress levels and are at different stages of material deterioration. The constitutive equations remain valid until the specified rupture criterion $\omega_{\mathrm{f}}=0.99$, is reached. At this time, the point under consideration can no longer sustain load and, at this point (or element) the material has failed. Ultimately a region of failed material will progress through the body until the applied load can no longer be sustained and the body fails as a whole.

\begin{tabular}{|c|c|c|c|c|}
\hline $\begin{array}{c}\text { Temperature } \\
\left({ }^{\circ} \mathbf{C}\right)\end{array}$ & Specimen & P (MPa) & F (N) & Lifetime (h) \\
\hline 640 & AKF011 & 8.917 & 13680 & 3992 \\
\hline 620 & AKF001 & 12.133 & 18922 & 3063 \\
\hline 600 & AKF009 & 15.544 & 24232 & 2937 \\
\hline 575 & AKF006 & 15.487 & 24103 & 12871 \\
\hline
\end{tabular}

Table 4a: Summary of experimental results for butt-welded pipe.

\begin{tabular}{|c|c|c|c|}
\hline $\begin{array}{c}\text { Temperature } \\
\left({ }^{\circ} \mathbf{C}\right)\end{array}$ & Specimen & $\sigma^{+}$(MPa) & Lifetime (h) \\
\hline 640 & AKF23 & 40 & 2991 \\
\hline 640 & AKF13 & 54.1 & 894 \\
\hline 640 & AKF15 & 69.5 & 465 \\
\hline 620 & AKF22 & 40 & 5845 \\
\hline 620 & AKF18 & 54.1 & 2385 \\
\hline 620 & AKF14 & 69.5 & 1308 \\
\hline 600 & AKF19 & 54.1 & 6690 \\
\hline 600 & AKF17 & 69.5 & 3223 \\
\hline 575 & AKF20 & 69.5 & 11558 \\
\hline
\end{tabular}

Table 4b: Summary of experimental results for uni-axial cross-weld testpieces

The numerical procedure used to solve the boundary value problem for creep damage and deformation is that used by Hayhurst et al (1984a \& b). It is based on the finite element method and employs constant strain triangular elements, which have been extensively used to model the behaviour of notched and creep crack components. The finite element mesh generator package, FEMGEN (2001) was used to generate the meshes. The solution method 
takes the elastic solution as its starting point: the elastic strains being computed from $\varepsilon_{\mathrm{ij}}^{\mathrm{e}}=\mathrm{C}_{\mathrm{ijkl}} \sigma_{\mathrm{kl}}$ where $\mathrm{C}_{\mathrm{ijkl}}$ is the matrix of the elastic constants. The total strains are composed of the elastic, $\varepsilon_{\mathrm{ij}}^{\mathrm{e}}$, and creep, $\varepsilon_{\mathrm{ij}}^{\mathrm{c}}$, strains, and with the creep damage variables $\mathrm{H}$, $\Phi, \omega$, being integrated with respect to normalised time. The integration is carried out over a series of discrete normalised time steps using a fourth order Runge-Kutta technique; this procedure involves the repeated solution of the boundary value problem to determine the field quantities required for the numerical solution. Creep damage, as represented by the two damage state variables, develops monotonically in time throughout the structure, and failure of an element is deemed to have occurred when the second damage state variable $\omega$ attains the prescribed value. The material element is then unable to transmit or sustain load and is removed from the model. The boundary value problem is redefined, the time integration is continued by taking the new starting point as the field variables before the local failure occurred. The procedures are then repeated until complete failure of the cracked member occurs.

The loaded boundary of the specimens, c.f. Figures $3 \& 4$, were subjected to constant stresses and forces. The computations were carried out on a multiprocessor SUN computer. The computed results of stresses, strains, displacements, damage state variables and times to failure were stored for subsequent examination by the post processor FEMVIEW (2001).

\subsection{Butt-Welded Pipes}

The finite element mesh for the butt-welded pipe, Figure 3, had 19 elements through the pipe thickness and 4 through the thickness of the Type IV zone. The thickness of the Type IV zone as specified by Dean (2001) is $1.0 \mathrm{~mm}$, all other dimensions are specified in Figure 3. The 2-D axysymmetric version of Damage XX, Hayhurst el al (1984a \& b) has been used. Test data are summarised in Table 4a.

\subsection{Crosswelded Uni-axial Testpieces}

The finite element mesh for the crosswelded testpiece, Figure 4, had 13 elements through the testpiece thickness and 3 through the thickness of the Type IV zone. The thickness of the Type IV zone as specified by Dean (2001) is $1.0 \mathrm{~mm}$, all other dimensions are specified in Figure 4. The Type IV zone thickness of $1 \mathrm{~mm}$ was measured using optical techniques. Test data are summarised in Table 4b. The minimum cross-section stress is denoted by $\sigma^{+}$. Damage XX, Hayhurst el al (1984a \& b) has been used as for the butt-welded pipe.

Preliminary studies have shown that plane stress models are inappropriate and show insufficient sensitivity to variation in the multi-axial stress rupture parameter $\nu$. All modelling has therefore been carried out using assumptions of plane strain.

\subsection{PRESENTATION OF CDM ANALYSIS RESULTS AT $640^{\circ} \mathrm{C}$ AND CALIBRATION OF TYPE IV THICKNESS AND MULTI-AXIAL STRESS RUPTURE PARAMETER $v$}

The initial value of the Type IV thickness was specified as $1.0 \mathrm{~mm}$ as discussed in Section 5.1 and 5.2. This value was taken from the average measurements taken from micrographs (Dean, 2001). With regard to the value of Type IV thickness to be used in CDM analyses, one would expect a reduction in thickness depending on the extent of stress redistribution; the latter would be most pronounced for the increased creep strain rates at the 
higher temperature of $640^{\circ} \mathrm{C}$. It is for this reason that the $\mathrm{CDM}$ analyses have been carried out at $640^{\circ} \mathrm{C}$.

In the following section, results will be presented for Type IV thickness values in the range of $0.25-3.00 \mathrm{~mm}$, and for values of the multi-axial stress rupture parameter $v$ in the range 2 - 2.8. The analyses have been carried out for $640^{\circ} \mathrm{C}$ without the presence of CoarseGrained Heat Affected Zone.

Presented in Figure 5 are spatial variations of the damage parameter $\omega$ close to failure over a diametral plane, Figure $5 \mathrm{a}$, for $\mathrm{t}=0.25 \mathrm{~mm}$ in the case of the butt-welded pipe; and, over a mid-plane cross-section, Figure $5 b$, for the uni-axial crosswelded testpiece with $t=$ $1.25 \mathrm{~mm}$. In both cases the failure takes places, as expected in the Type IV region.

In order to assess the ability of the CDM analyses to predict the experimental lifetimes of either pipe or crossweld testpiece the following normalised parameter is introduced:

$$
\lambda=\text { Predicted Lifetime/Experimental Lifetime. }
$$

This parameter is plotted in Figure 6 against the multi-axial stress rupture parameter $v$. The target zone for the predicted results is given by the shaded band. The results for the pipe (AKF011) are given by the broken lines, and those for the crossweld testpiece by the solid lines. Candidate values are clearly $\nu=2.0$ for both geometries, with Type IV thicknesses of $t$ $=0.25 \mathrm{~mm}$ for the pipe and $\mathrm{t}=1.25 \mathrm{~mm}$ for the crosswelded testpiece. For all CDM predictions related to Figure 5, and to the broader set covered by Figure 6, failure was predicted, in all cases, to take place in the Type IV region. To examine with more precision the values to be selected, a further plot or normalised lifetime $\lambda$ against Type IV thickness $t$ is presented in Figure 7. The target zone is shown by the shaded band; clearly the curves for $v=2.8$ can be rejected. If the curves for $v=2.0$ are averaged to yield the curve given by the solid squares, then this curve intersects the target band at a Type IV thickness $t=0.7 \mathrm{~mm}$. This is the value which has been selected for use in all further CDM studies, for welds with this particular ferritic parent and weld material.

\subsection{PRESENTATION OF CDM ANALYSIS RESULTS AND THE DETERMINATION OF TYPE IV $v$ VALUES FOR DIFFERENT TEMPERATURES AND STRESSES}

Having determined the Type IV thickness to be $t=0.7 \mathrm{~mm}$ for the purpose of CDM analysis, it is necessary to determine the value of the multi-axial stress rupture parameter $v$ for all specimens tested at different temperatures and loading conditions. Since the 2-D CDM analyses could be carried out quickly for both pipes and crosswelded testpieces it was possible to carry out the large number of analyses required to achieve this.

The chosen strategy was to select each one of the four temperatures 575, 600, 620 and $640^{\circ} \mathrm{C}$ and to determine the value of $v$ required to give $\lambda=1$ for each specimen tested. The values of Type IV $\nu$, determined in this way are given in Table 1; the determination of the Type IV $v$ value for $590^{\circ} \mathrm{C}$ is discussed later in this section. The first observation made was that at a single temperature the value of $v$ was dependent upon stress level and state. It was found that results for pipes and crosswelded testpieces correlated best by using the effective stress $\sigma_{\mathrm{e}}$; and, in addition a convenient correlation was achieved by normalising $\sigma_{\mathrm{e}}$ using the stress $\sigma_{0}$, defined as the uni-axial stress required to give $1000 \mathrm{hr}$ lifetime at the temperature under consideration. The value of this stress was determined by integration of the uni-axial form of equation 1 and the constitutive parameters, given in Table 1. When processed in this 
way the results, for the four temperatures, may be plotted as shown in Figure 8. The solid lines are the best fits given by:

$$
\nu=\mathrm{a}\left\{\exp \left(\mathrm{b} \sigma_{\mathrm{e}} / \sigma_{\mathrm{o}}\right)\right\}
$$

where the coefficients $\mathrm{a}$ and $\mathrm{b} \sigma_{\mathrm{o}}$ and values of are given in Table 5.

The following empirical equations have been used to obtain values of $a$ and $b$ for the temperatures 540, 565, 575, 590, 600, 620 and $640^{\circ} \mathrm{C}$ :

$$
\begin{aligned}
& \mathrm{a}=\{0.5241 \ln [(1 / \mathrm{T})-0.001082]\}+7.1791 \\
& \mathrm{~b}=\{0.5466 \ln [(1 / \mathrm{T})-0.001090]\}+7.2253
\end{aligned}
$$

where the temperature $\mathrm{T}$ is given in ${ }^{\circ} \mathrm{K}$.

\begin{tabular}{|l|c|c|c|c|c|c|c|}
\hline & $\mathbf{5 4 0}^{\circ} \mathbf{C}$ & $\mathbf{5 6 5}^{\circ} \mathbf{C}$ & $\mathbf{5 7 5}^{\circ} \mathbf{C}$ & $\mathbf{5 9 0}^{\circ} \mathbf{C}$ & $\mathbf{6 0 0}^{\circ} \mathbf{C}$ & $\mathbf{6 2 0}^{\circ} \mathbf{C}$ & $\mathbf{6 4 0}^{\circ} \mathbf{C}$ \\
\hline $\mathbf{a}$ & 2.557473425 & 2.408152305 & 2.337320555 & 2.213265055 & 2.113747626 & 1.842372829 & 1.294253773 \\
\hline $\mathbf{b}$ & 2.374891698 & 2.2087667 & 2.12873492 & 1.986108997 & 1.868854285 & 1.529562129 & 0.584304211 \\
\hline $\begin{array}{l}\sigma_{\mathbf{0}} \\
\text { MPa }\end{array}$ & 217.997061 & 176.020536 & 159.940426 & 136.581511 & 121.516401 & 92.604181 & 65.315961 \\
\hline
\end{tabular}

Table 5: Parameters a and $b$ used to determine the multi-axial stress rupture parameter $v$ in the equation $v=\mathbf{a}\left\{\exp \left(\mathbf{b} \sigma_{\mathrm{e}} / \sigma_{0}\right)\right\}$ for the Type IV material. Values of the uni-axial stress $\sigma_{0}(\mathrm{MPa})$ are quoted to give $1000 \mathrm{hr}$ lifetime.

Hence, using the Type IV $v$ values given by equation 5 and the data of Table 5 , hightemperature multi-axial creep behaviour in ferritic steel welds composed of parent, Type IV, refined HAZ and weld materials can be accurately predicted. However, the four Type IV $v$ values, quoted in Table 1 for 575, 600, 620 and $640 \mathrm{PP}^{\circ} \mathrm{C}$, are the point values used to calibrate equation (5).

In the last section of the paper consideration will be given to the effect of including a further material zone, namely the Coarse Grained Heat Affected Zone CG-HAZ.

\subsection{CDM STUDIES ON THE EFFECT OF THE INCLUSION OF A COARSE GRAINED HEAT AFFECTED ZONE FOR BOTH PIPE AND CROSSWELDS}

As for the Type IV zone, the thickness of the CG-HAZ introduces a degree of uncertainty. However, since this investigation is intended as a preliminary sensitivity assessment the same level of care will not be exercised as for the Type IV zone. The CG-HAZ width has been determined by examination of surface macrographs for the pipes and midthickness micrographs for the crosswelded testpieces. The CG-HAZ width has been determined from six different pieces of evidence to be one-third of the total Heat Affected Zone width, namely the thickness for the pipe is $1.333 \mathrm{~mm}$, and for the crossweld testpiece the 
thickness varies linearly from $0.727 \mathrm{~mm}$ to $1.260 \mathrm{~mm}$. An example of a pipe surface micrograph which has been used to determine these values is given in Figure 9.

The values of the CG-HAZ constitutive parameters (A, B, C, h, $\mathrm{H}^{*}$ and $\mathrm{Kc}$ ) are given in Table 1, and they have been determined by Hayhurst, Mustata and Hayhurst (2003) from property ratios. Three such ratios were considered at $620^{\circ} \mathrm{C}$; the temperature at which studies were carried out on crosswelded tension testpieces and on internally butt-welded pressurised pipes for the property ratios given in Table 6 . The constitutive parameters given in Table 1 correspond to a minimum strain rate ratio of 3.4 given in the first row of Table 6 .

\begin{tabular}{|c|c|c|}
\hline $\mathrm{t}_{\mathrm{f} \text { parent }} / \mathrm{t}_{\mathrm{fCG}-\mathrm{HAZ}}$ & $\dot{\varepsilon}_{\text {min parent }} / \dot{\varepsilon}_{\text {min CG }-\mathrm{HAZ}}$ & $\varepsilon_{\mathrm{f} \text { parent }} / \varepsilon_{\mathrm{f} \mathrm{CG}-\mathrm{HAZ}}$ \\
\hline 1.09 & 3.4 & 3.33 \\
\hline 0.95 & 6.0 & 5.90 \\
\hline 0.96 & 10.0 & 9.90 \\
\hline
\end{tabular}

Table 6: Property ratios for Coarse-Grained HAZ material achieved after constitutive parameter optimisation at $620^{\circ} \mathrm{C}$

The latter set of property ratios was determined following CDM analysis of pipe and crossweld testpieces. For both the pipes and crosswelded testpieces failure took place in the Type IV region, as observed in the metallurgical examinations; and, slight CG-HAZ damage was observed.

In the case of the constitutive parameters for minimum creep ratios of 6 and 10 , defined in rows two and three of Table 6, the bias of damage to the CG-HAZ region was too dominant; and, the lifetimes were underestimated, hence the constitutive parameters corresponding to these ratios were rejected.

\begin{tabular}{|c|c|c|}
\hline \multirow{2}{*}{ Temp $^{\circ} \mathbf{C}$} & PIPES \\
\cline { 2 - 3 } & Experimental Lifetime & Predicted Lifetime \\
\hline 640 & 3818 & 3812 \\
\hline 620 & 3063 & 3786 \\
\hline 600 & 2937 & 2868 \\
\hline 575 & 12871 & 13066 \\
\hline \multirow{2}{*}{ Temp $^{\circ} \mathbf{C}$} & \multicolumn{2}{|c|}{ CROSS-WELDS } \\
\cline { 2 - 3 } & Experimental Lifetime & Predicted Lifetime \\
\hline 640 & 465 & 414 \\
\hline 620 & 1308 & 1206 \\
\hline 600 & 3223 & 10545 \\
\hline 575 & 11558 & \\
\hline
\end{tabular}

Table 7: Comparison of experimental and CDM lifetimes predicted using Damage XX, for butt-welded pipes at selected internal pressures and stresses. Cross-weld tests are carried out at a minimum cross-section stress of $69.5 \mathrm{MPa}$. 
The ability of the selected CG-HAZ constitutive parameter set to predict damage fields at failure is shown in Figure 10, for the pipe, and in Figure 11, for the crossweld testpiece. The predicted damage field for the pipe at $600^{\circ} \mathrm{C}$ is shown in Figure 10 (a) where damage of the level of 0.99 (i.e. material failure value) can be observed. The surface macrograph of Figure 10(b) clearly shows both Type IV and CG-HAZ cracking, but with the former showing dominance. The predicted lifetime is $2868 \mathrm{hr}$ and the experimental value is $2937 \mathrm{hr}$, hence close agreement has been achieved.

In Figure 11 predicted damage fields are compared with a micrograph for a crossweld testpiece tested at $600^{\circ} \mathrm{C}$. Figure 11 (a) shows both Type IV regions with significant damage, which is corroborated by the micrographical evidence of Figure 11(b). Little CG-HAZ damage is evident in the CG-HAZ regions of Figure 11(a), although there is a hint of CGHAZ damage in the micrograph of Figure 11(b). The predicted lifetime is $2737 \mathrm{hr}$, and the experimental value is $3223 \mathrm{hr}$; hence close agreement has been achieved.

Comparisons are made of predicted and experimental values of lifetimes in Table 7 for both pipes and crossweld testpieces where close agreement may be observed.

\subsection{CONCLUSIONS}

1. Multi-axial constitutive equation parameters have been summarised for the temperatures 575, 590, 600, 620 and $640^{\circ} \mathrm{C}$.

2. Multi-axial stress rupture parameters $v$ have been discussed and summarised for five temperatures given in 1 above.

3. The thickness of the Type IV zone has been determined to be $0.7 \mathrm{~mm}$ for the purpose of CDM analysis.

4. Values of the multi-axial stress rupture criterion $v$ for the Type IV region have been found to be temperature and stress level dependent. A convenient interpolation formula has been presented.

5. The constitutive parameters have been used to accurately predict both lifetimes and damage distributions for pipes and crossweld testpieces.

6. A CG-HAZ thickness of one-third the total HAZ width has been determined from micrographs; and CDM analyses have been carried out to show that the selected constitutive parameter set, which corresponds to CG-HAZ minimum creep rate being equal to $1 / 2.5$ of the corresponding parent values, provides good predictions of lifetime and damage distributions.

7. A complete set of constitutive parameters for parent, Type IV, HAZ, CG-HAZ and weld materials has been established for the analysis of a welded medium bore ferritic branch tested at $590^{\circ} \mathrm{C}$.

\section{ACKNOWLEDGEMENTS}

The results of the calculations presented in this paper have been obtained by R J Hayhurst, EPSRC (RAIS) secondment from UMIST to British Energy, Barnwood. The provision of creep data and metallographic information, together with support regarding data interpretation, by Dr D Dean and Mr M Spindler of British Energy, Barnwood, Gloucester, is gratefully acknowledged. Acknowledgement for permission to publish the creep test results is given to the sponsors of the ERA Technology Project - 4080 from which the data originates, in particular ALSTOM Power (UK) Ltd, British Energy plc, and PowerGen plc. The provision of EPSRC, CSAR, computer resource on the Silicon Graphics Origin 2000 (Fermat) is gratefully acknowledge. 


\section{REFERENCES}

BROWNE, R J, FLEWITT, P E J, LONSDALE, D, SHAMMAS, M S; SOO, J N, (1981) Multiaxial Creep of Fine Grained $0.5 \mathrm{Cr}--0.5 \mathrm{Mo}-0.25 \mathrm{~V}$ and Coarse Grained $1 \mathrm{Cr}-0.5 \mathrm{Mo}$ Steels, Materials Science and Technology. 7, 8, 707-717. Aug. 1991.

CANE, B J (1981) Collaboration programme on the correlation of test data for high temperature design of welded steam pipes. Presentation and analysis of the material data. Note No. RD/L/2101N81, March, CEGB Laboratory.

COLEMAN, M C, PARKER, J D and WALTERS, D J (1985) The behaviour of ferritic weldments in thick section $0.5 \mathrm{Cr} 0.5 \mathrm{Mo} 0.25 \mathrm{~V}$ pipe at elevated temperature, Int. J. Pres. Ves. and Piping, 18, 277-310.

COLEMAN, M C (1988) High temperature behaviour of ferritic pipe welds: experience of long-term testing. The First Finnish Sea Symposium on Materials Aspects in Life Extensions of Power Plants, Helsinki, Stockholm, 19-22 September.

DEAN, D W (2001) Private Communication, British Energy plc, Barnwood, Gloucestershire. DYSON, B F and McLEAN, D (1977) Creep of nimonic 80 in torsion and tension. Metal. Sc. J. 11, 37-45.

FAIRMAN, A (1995) Preliminary metallographic findings of failed 0.5CrMoV uni-axial crossweld testpieces, ERA Technology Report MAP/64/95, February 1995.

FEMGEN \& FEMVIEW (2001) Finite element generation program, and post processor, Femgen and Femview are Tradenames of FEMSYS, St Albans Road, Leicester, LE2 1GF. GOOCH, D J, KIMMINS, S T, (1987) Type IV cracking in 0.5\% Cr, 0.5\%Mo, 0.25\% V 2.25\% Cr, 1\% Mo weldments, Creep and Fracture of Engineering Materials and Structures, Proc. 3rd In. Conf., Swansea; 5-10 Apr. 1987, 689-703.

HALL, F R and HAYHURST, D R (1991) Continuum damage mechanics modelling of high temperature and failure in a pipe weldment, Proc. R. Soc. Lond. A, 433, 383-403.

HAYHURT, D R (1972) Creep rupture under multi-axial states of stress, J. Mech Phys. Solids, 20, 381-390.

HAYHURST, D R., DIMMER, P R and MORRISON, C J (1984a) Development of continuum damage in the creep rupture of notched bars, Phil. Trans. R. Soc. Lond., A, 311, 103-129.

HAYHURST, D R., BROWN, P R and MORRISON, C J (1984b) The role of continuum damage in creep crack growth, Phil. Trans. R. Soc. Lond., A, 311, 131-158.

HAYHURST, D R and MILLER, D A (1994) The use of creep continuum damage mechanics to predict damage evolution and failure in welded vessels, IMechE S539/008 117-133.

HAYHURST D R and GOODALL I W (2003) Industrial drivers for the design and assessment of high temperature weldments: and, the use and capabilities of CDM analysis methods, Proc. of the $2^{\text {nd }}$ International Conference on Integrity of High Temperature Welds, Nov 2003, pp. 329-346, IOM Communications, London, ISBN 1-96125-160-2.

HAYHURST D R., HAYHURST, R J, and VAKILI-TAHAMI, F (2003) CDM predictions of creep damage initiation and growth in ferritic steel weldments in a medium bore branched pipe under constant pressure at $590^{\circ} \mathrm{C}$ using a 5-material weld model, UMIST Research Report DMM.03.05.

HAYHURST R J, MUSTATA R and HAYHURST D R (2003) Creep constitutive equations for parent, Type IV, HAZ, CG-HAZ and weld material in the range $565-640^{\circ} \mathrm{C}$ for welds composed of $0.5 \mathrm{Cr} 0.5 \mathrm{Mo} 0.25 \mathrm{~V}$ parent material and 2.25Cr $1 \mathrm{Mo}$ weld material, UMIST Research Report DMM.03.02. 
HAYHURST R J., VAKILI-TAHAMI, F and HAYHURST, D R (2003) Type IV and Coarse Grained HAZ creep rupture of ferritic steel uni-axially loaded crossweld testpieces: verification of 3-D parallel CDM software, DAMAGE XXX, using 2-D analyses and experiments. UMIST, Internal Research Report DMM.03.01

MILLER, D A, (2000) British Energy, Barnwood, Gloucs., UK, Private communication Re: 'Creep rupture testing of Cr Mo V pipe steel (ERA Project 63-01-040320009)'.

MUSTATA, R and HAYHURST D R (2001) Creep constitutive equations for 0.5Cr 0.5Mo $0.25 \mathrm{~V}$ parent ferritic steels in the temperature range $565-675^{\circ} \mathrm{C}$, UMIST Research Report DMM.01.06 (Revised).

MUSTATA, R., HAYHURST R J, VAKILI-TAHAMI F and HAYHURST D R (2003) CDM predictions of creep damage initiation and growth in ferritic steel weldments in a medium bore branched pipe under constant pressure at $590^{\circ} \mathrm{C}$ using a 4-material weld model, UMIST, Research Report DMM.03.04.

PERRIN, I J and HAYHURST, D R (1996) Creep constitutive equations for a 0.5Cr-0.5Mo$0.25 \mathrm{~V}$ ferritic steel in the temperature range $600-675^{\circ} \mathrm{C}$, Journal of Strain Analysis, 31, 299314.

PERRIN, I J and HAYHURST, D R (1999) Continuum Damage Mechanics analyses of Type IV creep failure in ferritic steel crossweld specimen, Int. J. Pres. Ves. and Piping, 76, 599617.

VAKILI-TAHAMI, R., HAYHURST, D R and WONG, M T (2003) High temperature creep rupture of low alloy ferritic steel butt-welded pipes subjected to combined internal pressure end loadings, Chapter 5 in: Reference Stress Methods - Analysing Safety and Design, Ed. Ian W Goodall, IMechE., Professional Eng. Pub., Bury ST Edmunds and London.

WALKER, N S, (1997) Type IV Creep Cavitiation in Low Alloy Ferritic Steel Weldments, PhD Thesis, University of Bristol, May 1997.

WALKER, N S, KIMMINS, S T and SMITH, D J, (1996) Type IV creep cavitation in ferritic steel welds Creep and Fatigue - Design and Life Assessment at High Temperature, Proceedings, 6th International Conference, Swansea, 15-17 Apr. 1996, 341-350.

WANG, Z P and HAYHURST, D R (1994) The use of super-computer modelling of hightemperature failure in pipe weldments to optimise weld and heat affect zone materials property selection, Proc. R. Soc. A, 446, 127-148. 


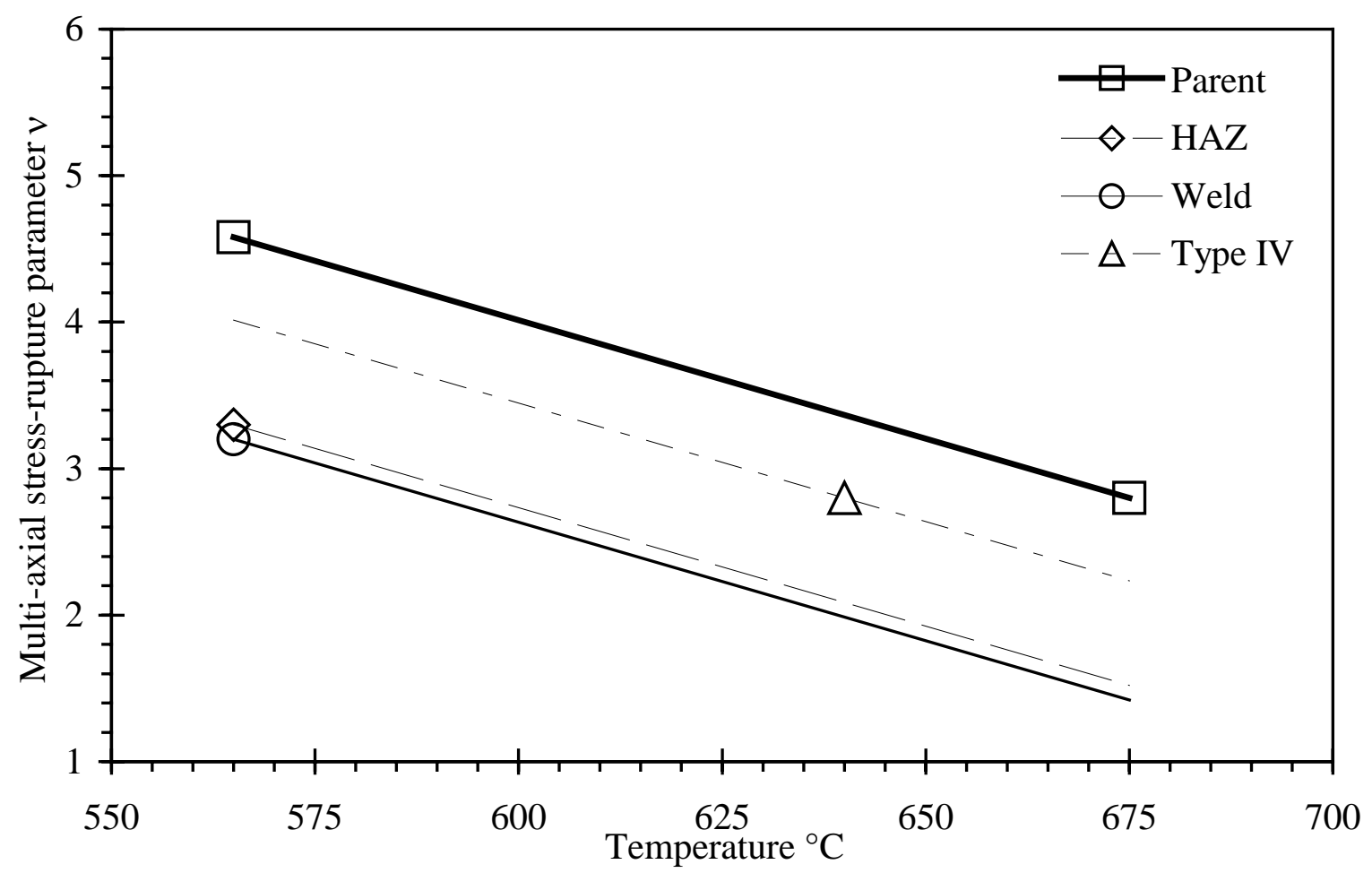

Figure 1: First estimates: Linearly interpolated values of the multi-axial stress rupture parameter $v$.

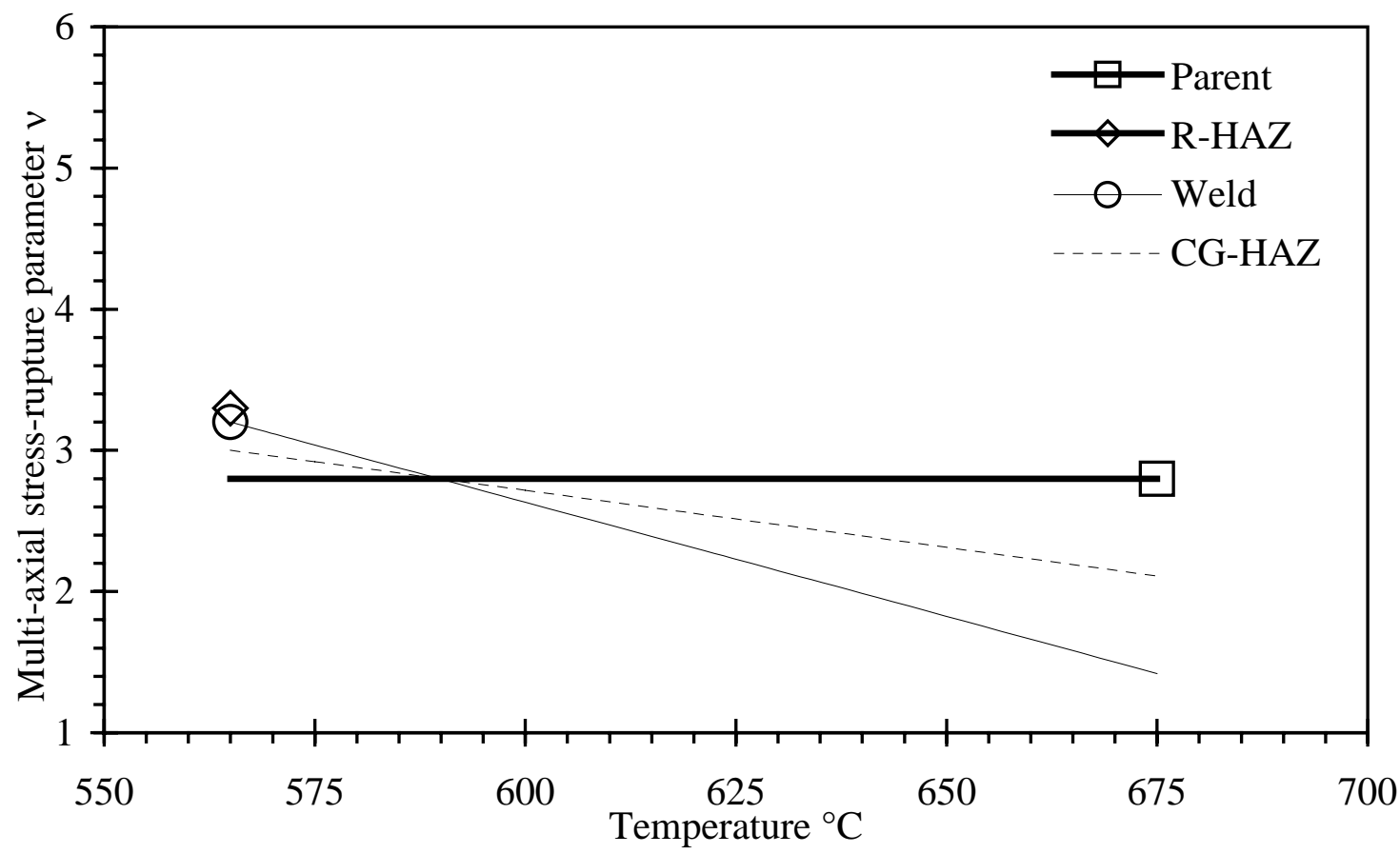

Figure 2: Revised estimates: Linearly interpolated values of the multi-axial stress rupture parameter $v$. 


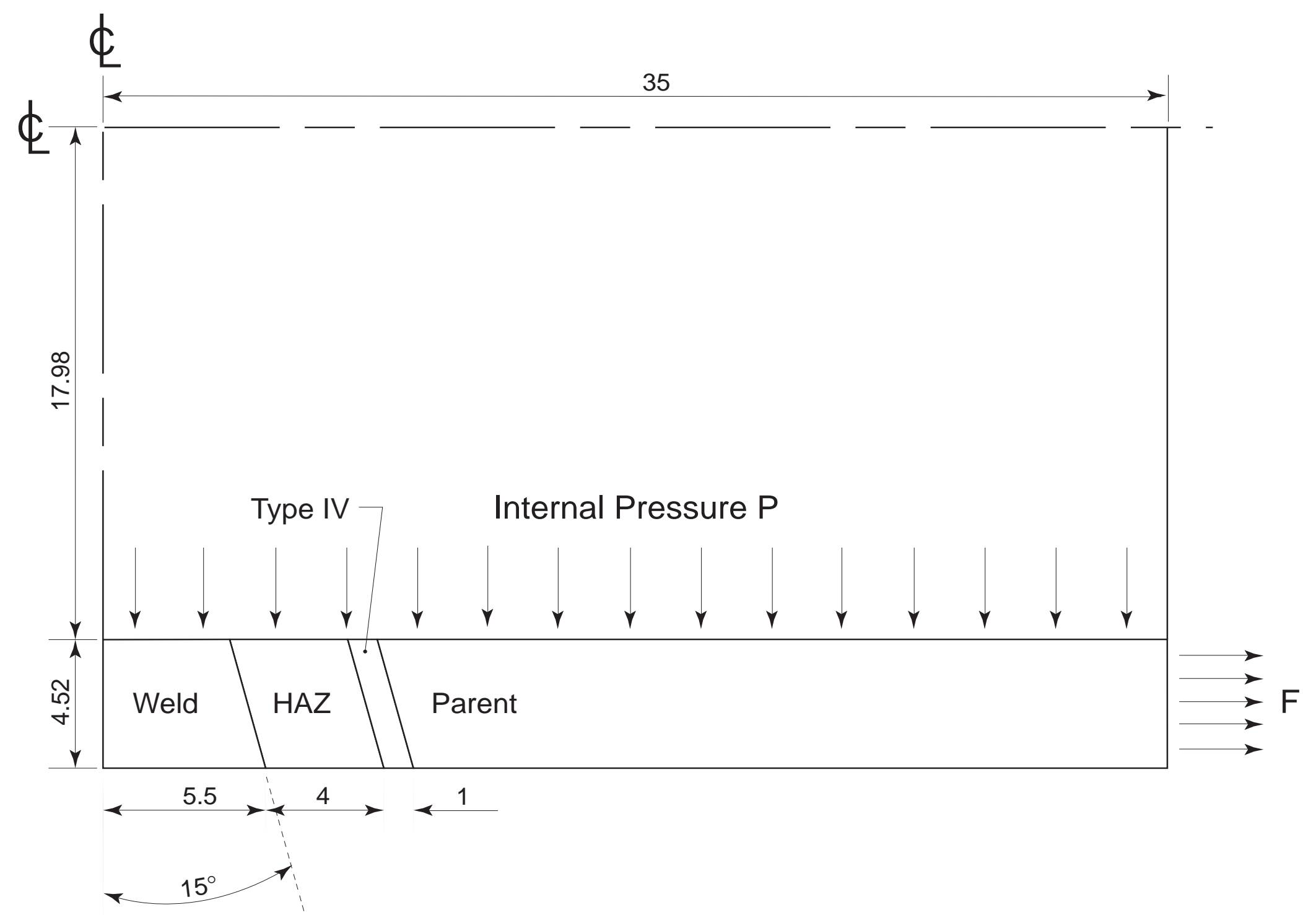

Figure 3: Geometry of butt-welded pipe and applied internal pressure P (MPa) and independently applied load F(N). All dimensions are in $\mathbf{~ m m}$. 


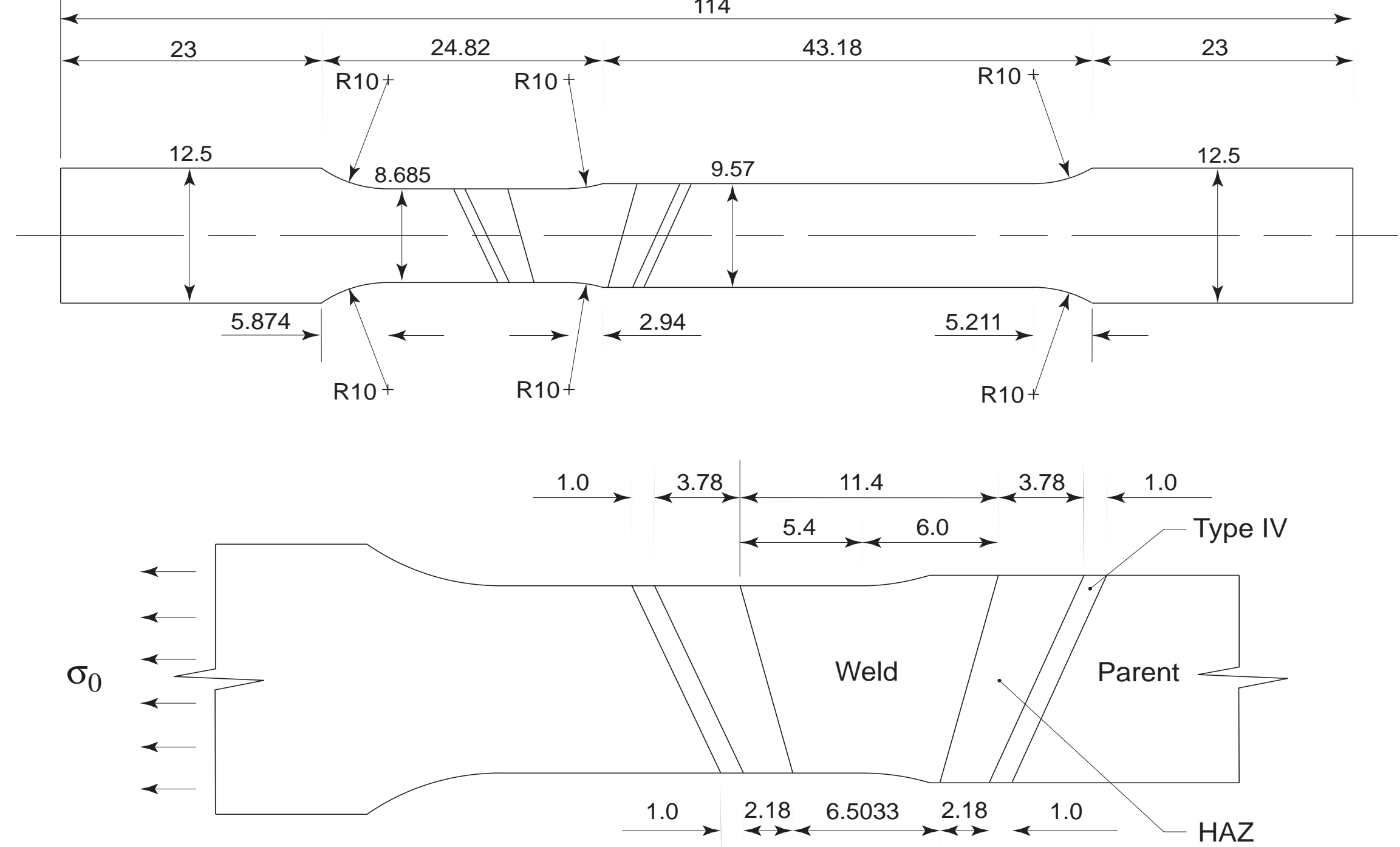

Figure 4: Geometry of uni-axial circular cross-welded testpiece and applied uniform stress, $\sigma$, diameter of testpiece loading shanks is 12.5mm. All Dimensions are in $\mathrm{mm}$. 

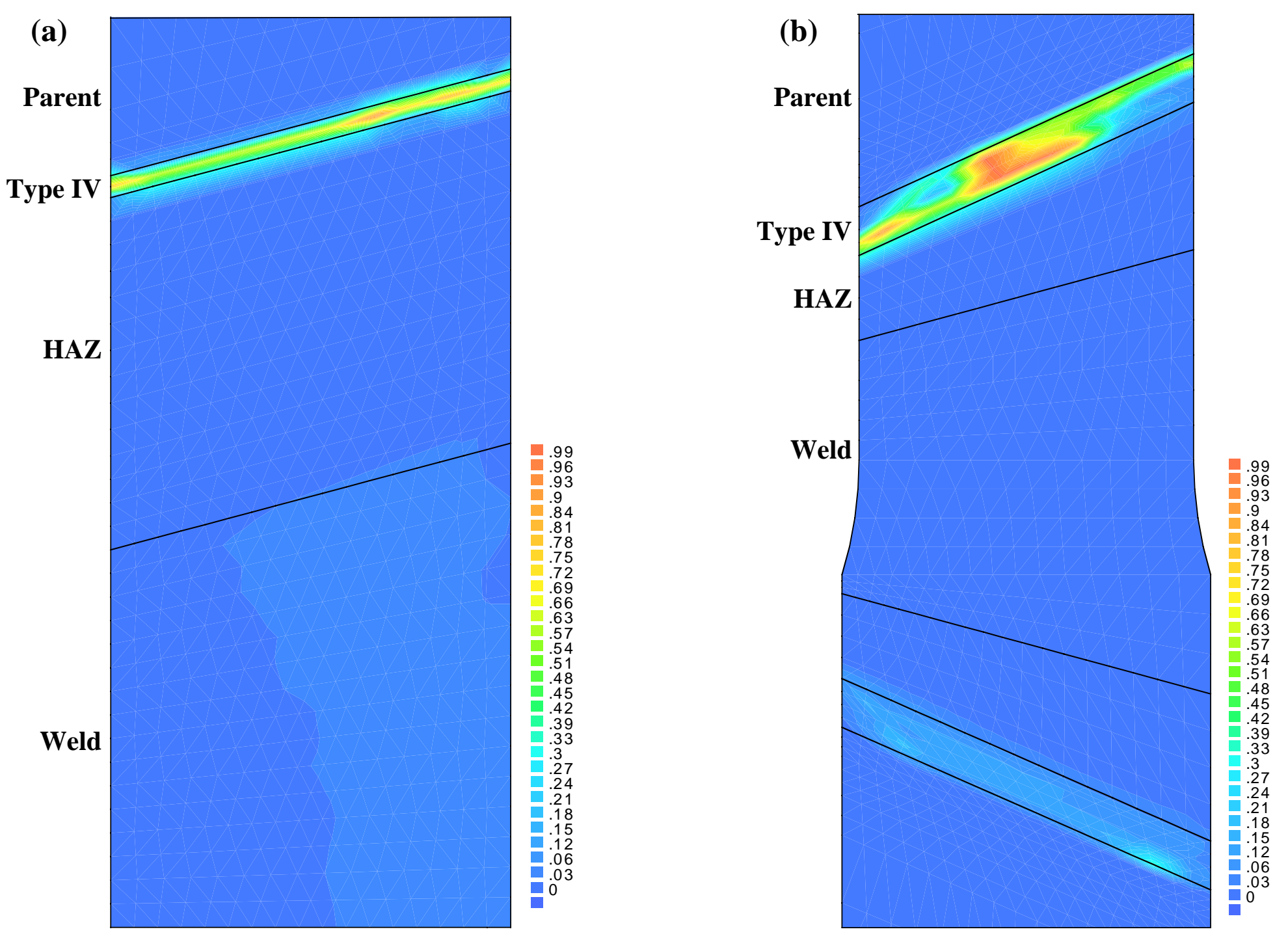

Figure 5: Spatial variation of the damage parameter $\omega$ over a selected region of; (a) a diameteral plane of the butt-welded pipe with a Type IV thickness of $0.25 \mathrm{~mm}$, close to failure, and (b) a plane cross-section of the uni-axial cross-weld with a Type IV thickness of $1.25 \mathrm{~mm}$, close to failure. Both simulations have been carried out with a Type IV a $v$ value of 2.0. 


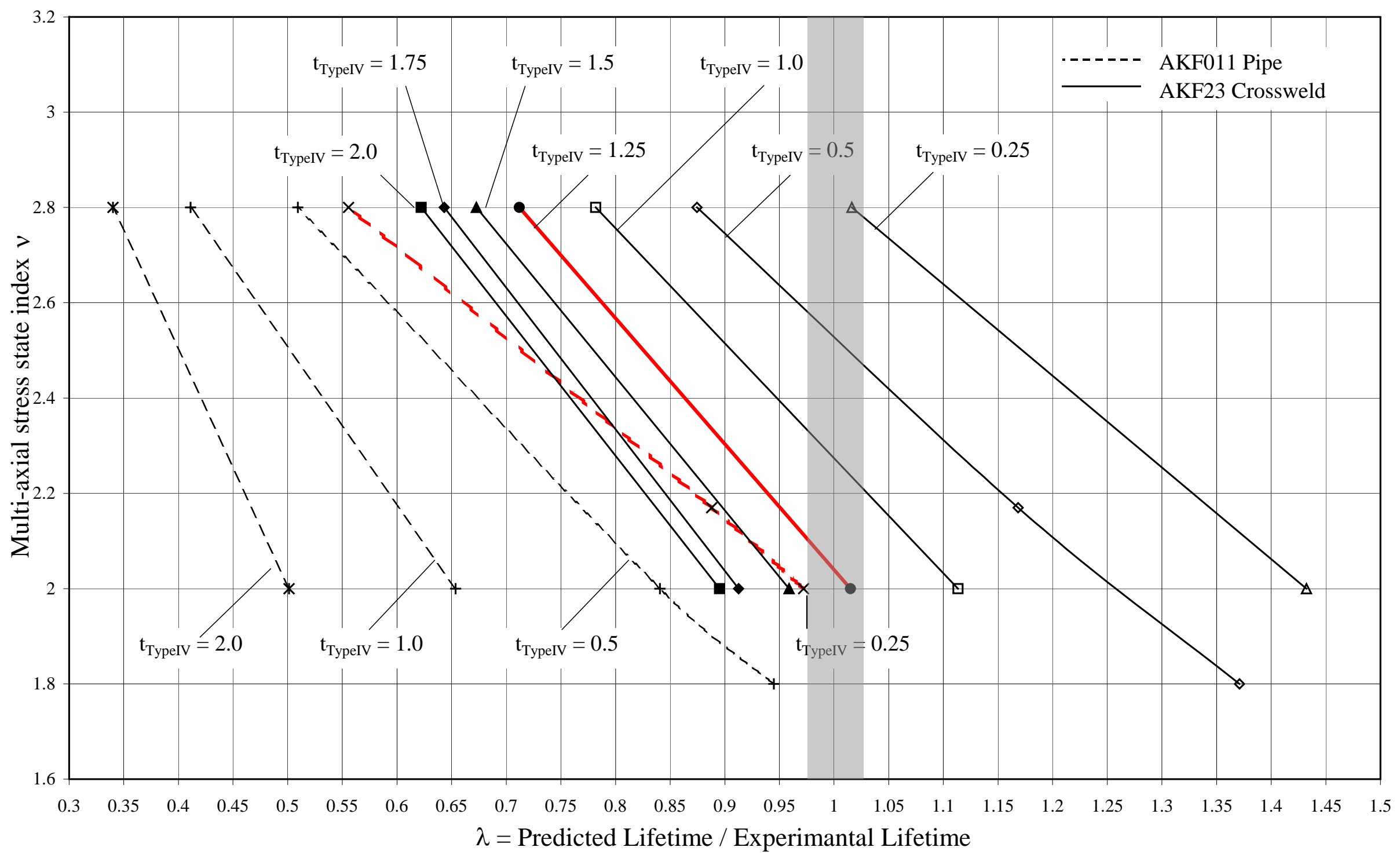

Figure 6: Variation of predicted normalised lifetime with multi-axial stress rupture index $v$ for different values of Type IV thickness at $640^{\circ} \mathrm{C}$. The solid lines denote cross-weld testpiece AKF23, and the broken lines denote internally pressurised pipe AKF011. 


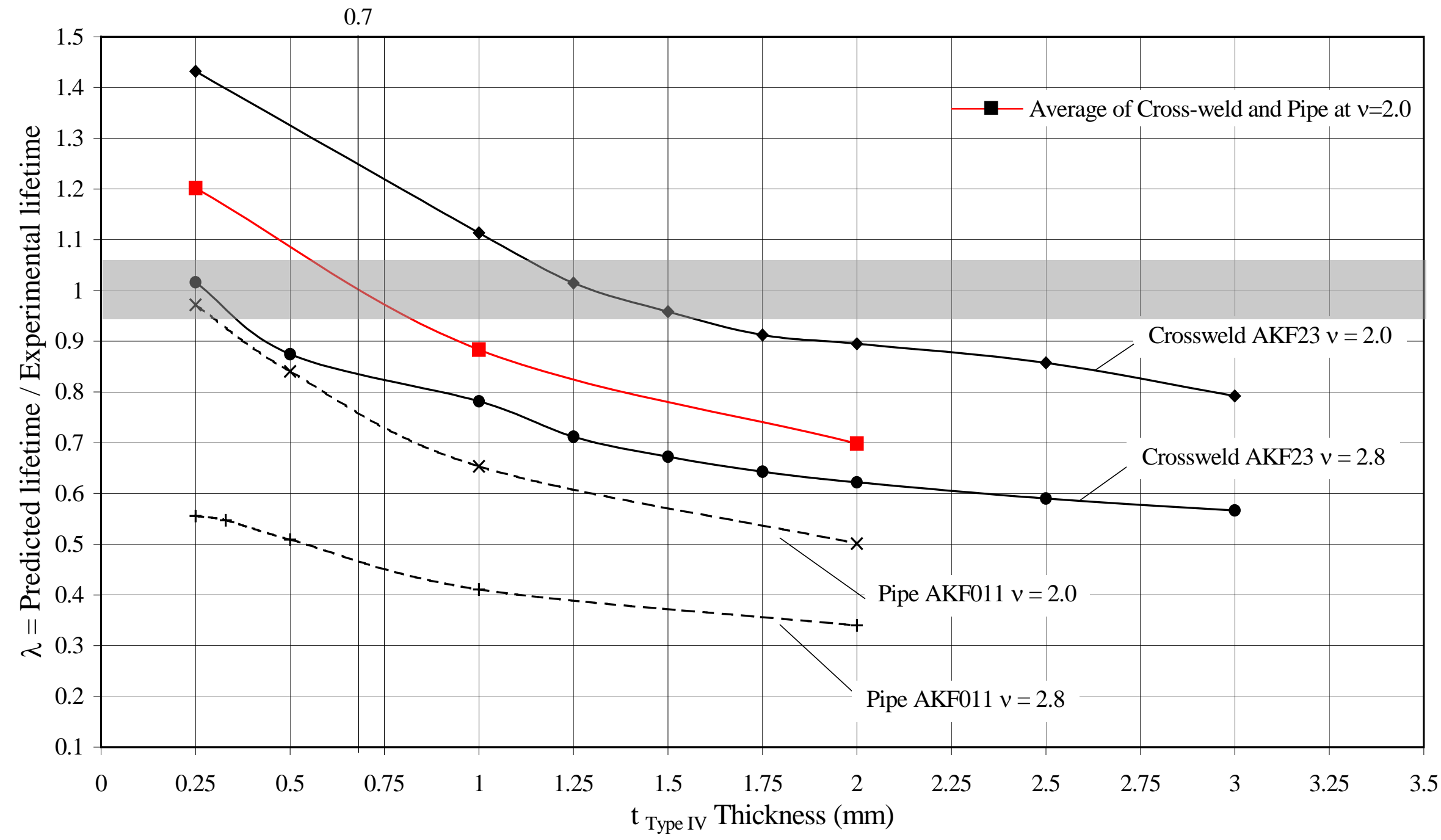

Figure 7: Variation of predicted normalised lifetime with Type IV zone thickness for $v=2.0$ and $v=2.8$ at $640^{\circ} \mathrm{C}$. The solid lines denote cross-weld testpiece AKF23, and the broken lines denote internally pressurised pipe AKF011. 


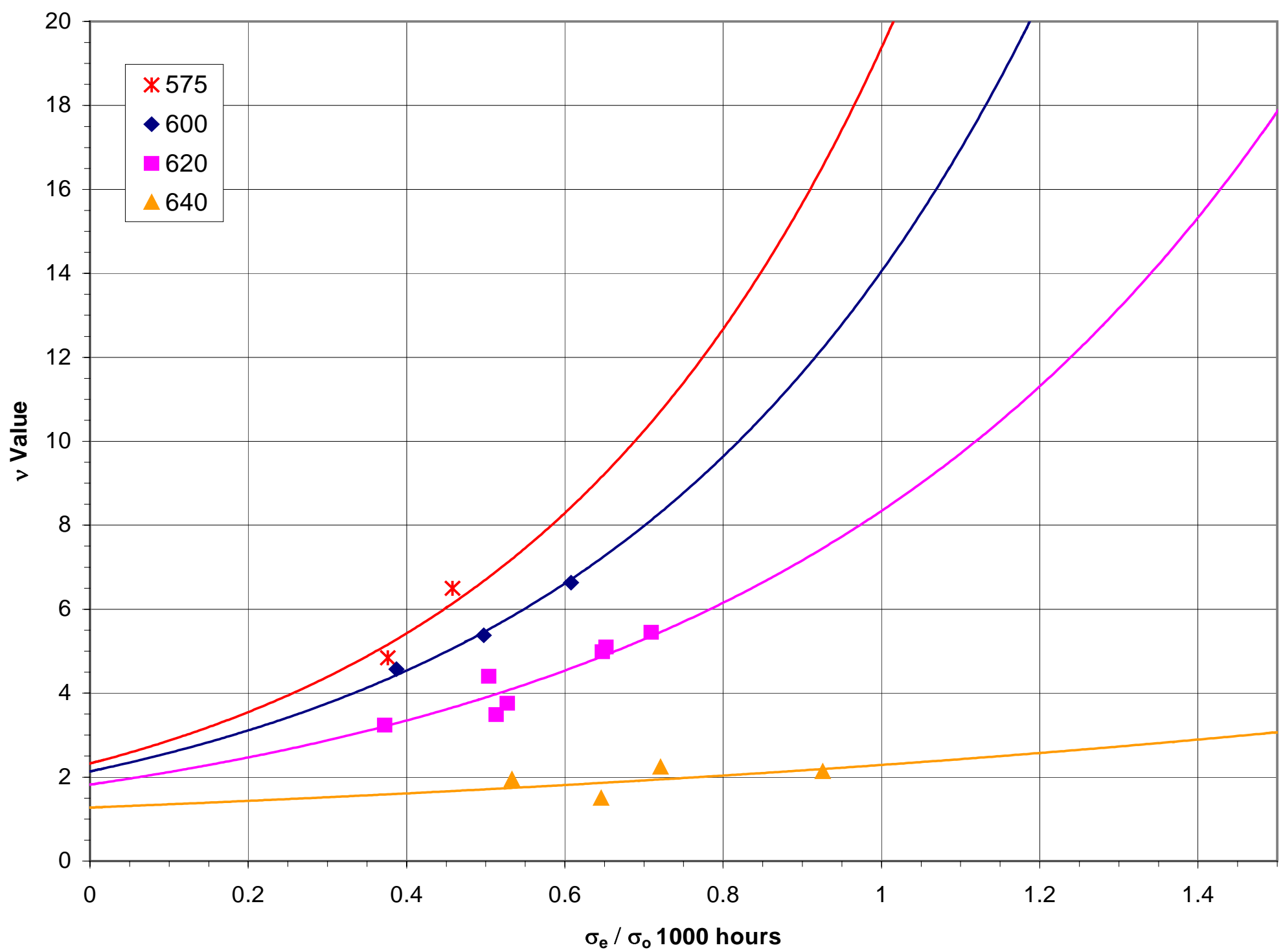

Figure 8: $v$ values for $575,600,620,640^{\circ} \mathrm{C}$ for normalised effective stress. The normalising stress is given for a 1000 hour lifetime. 


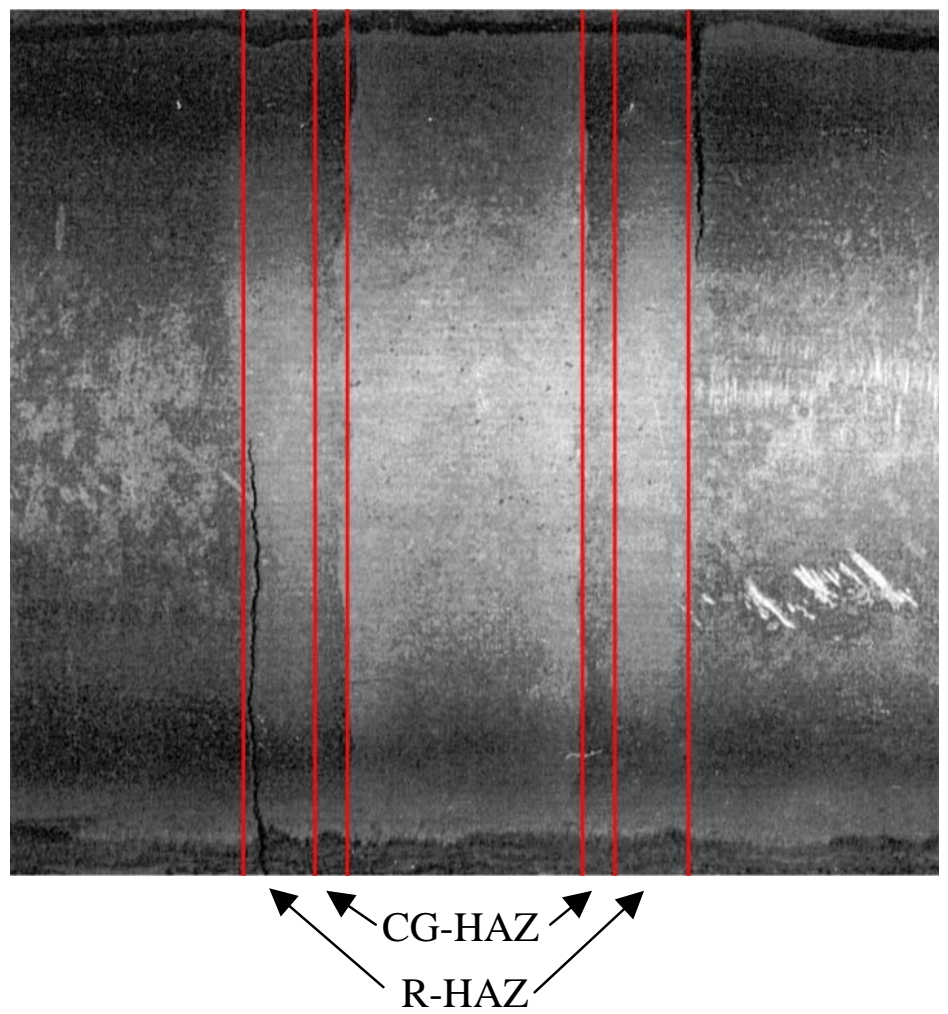

Figure 9: Macrograph of a pipe showing the Refined HAZ and Coarse Grained HAZ widths marked in red. 


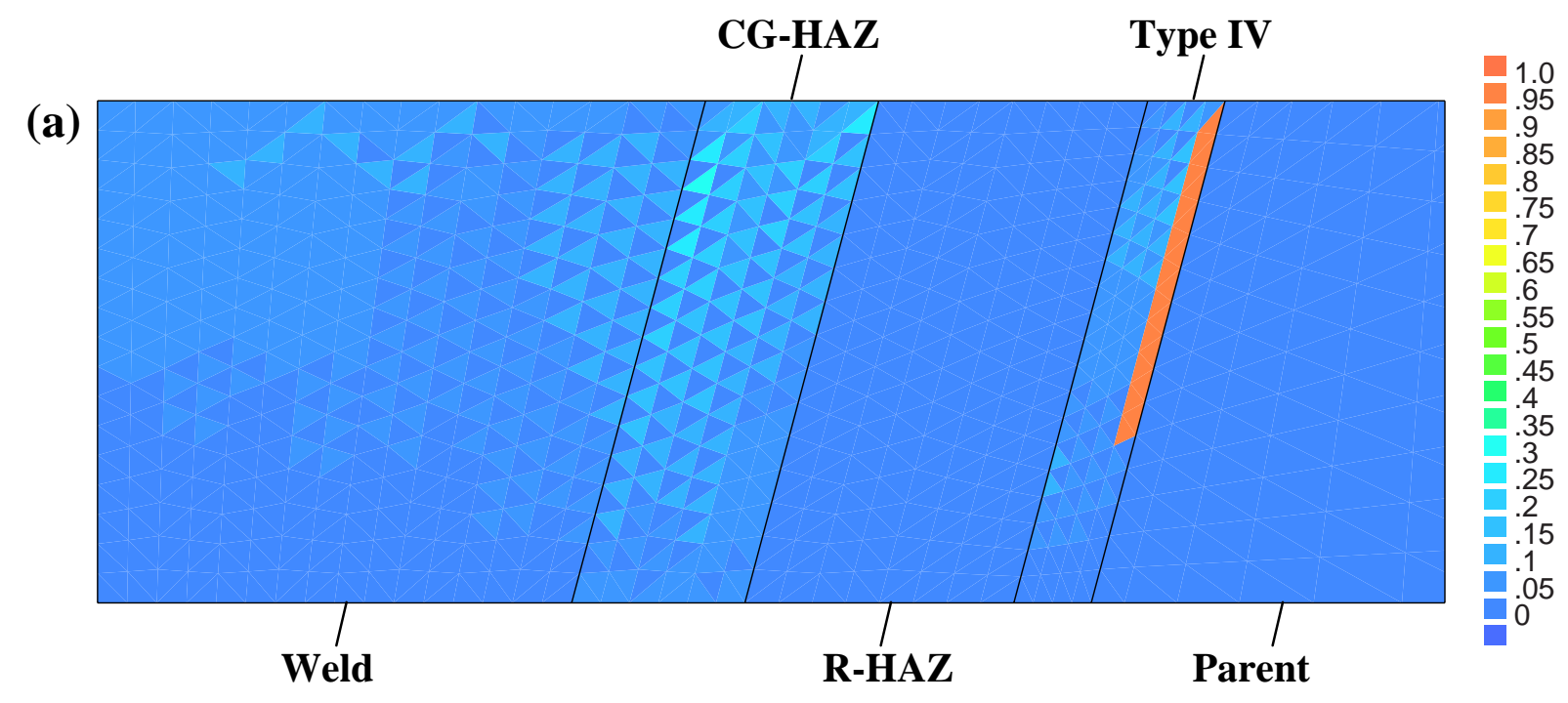

(b)

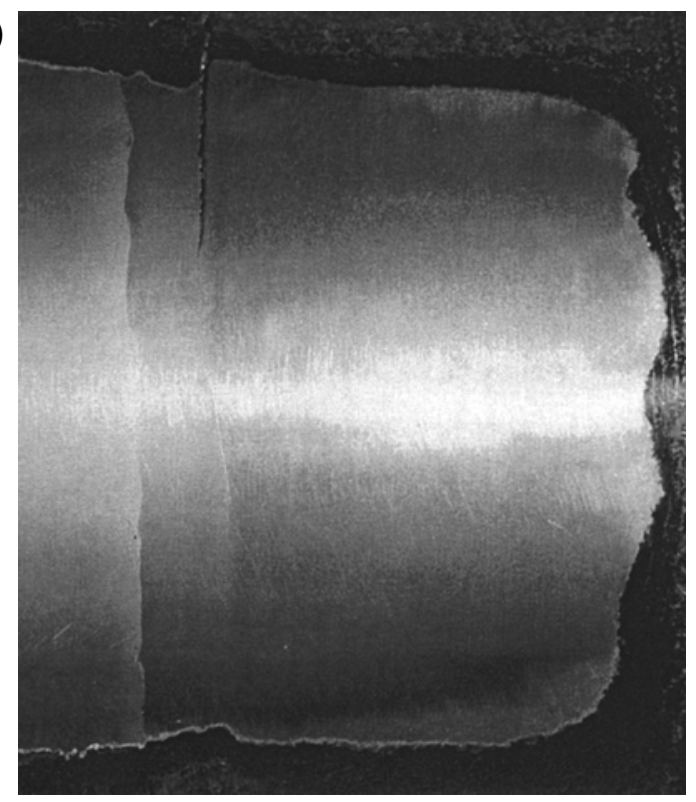

Figure 10: Comparison of predicted damage fields close to failure $t / t_{r}=0.99$, for (a) a diametral cross section of a butt-welded pipe subjected to an internal pressure of $15.544 \mathrm{MPa}$ and an end load of $24.232 \mathrm{kN}$ at $600^{\circ} \mathrm{C}(2868 \mathrm{hr})$, the left hand edge of the figure is the weld centre line, with (b) a macrograph taken from the surface of the failed testpiece $(2937 \mathrm{hr})$. 
(a)

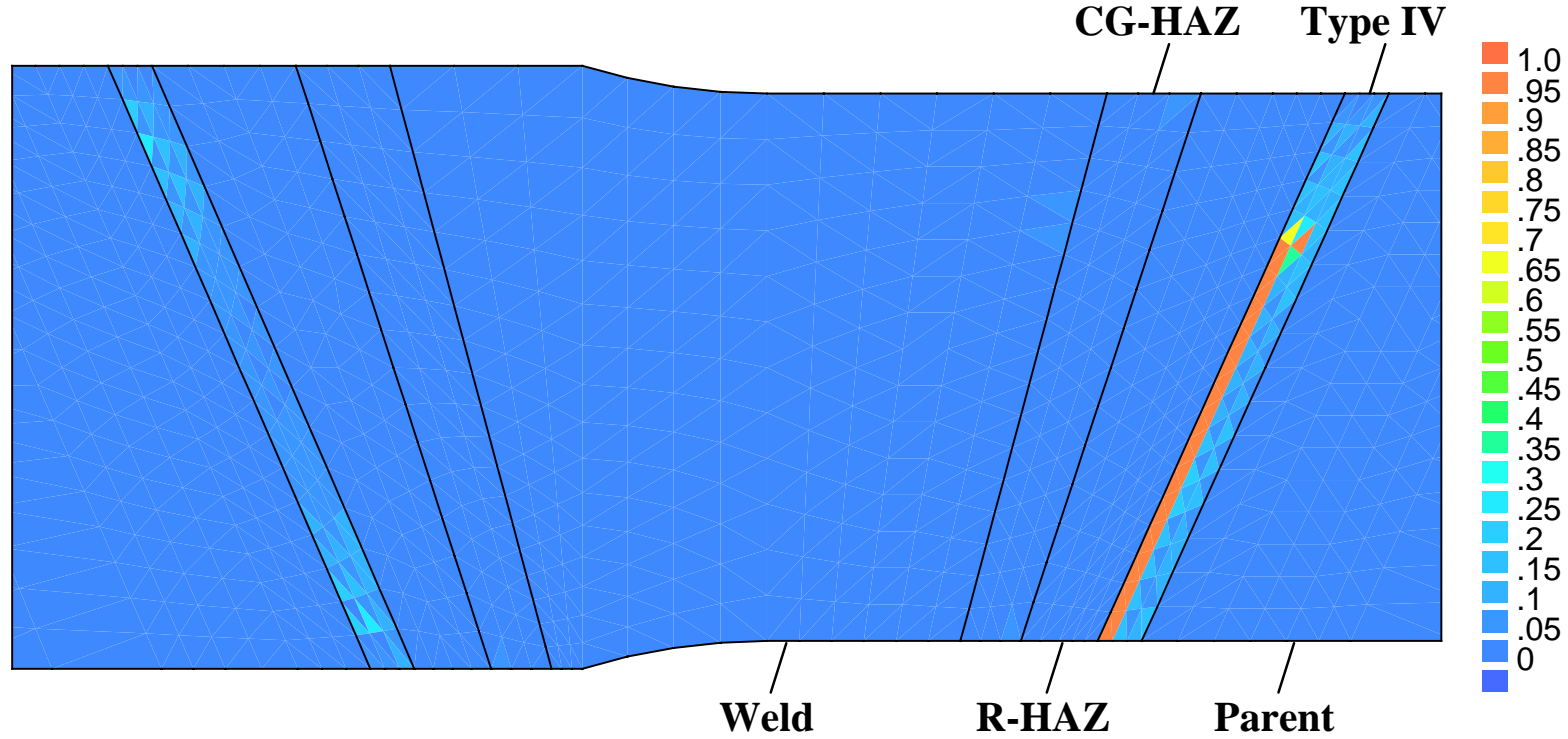

(b)

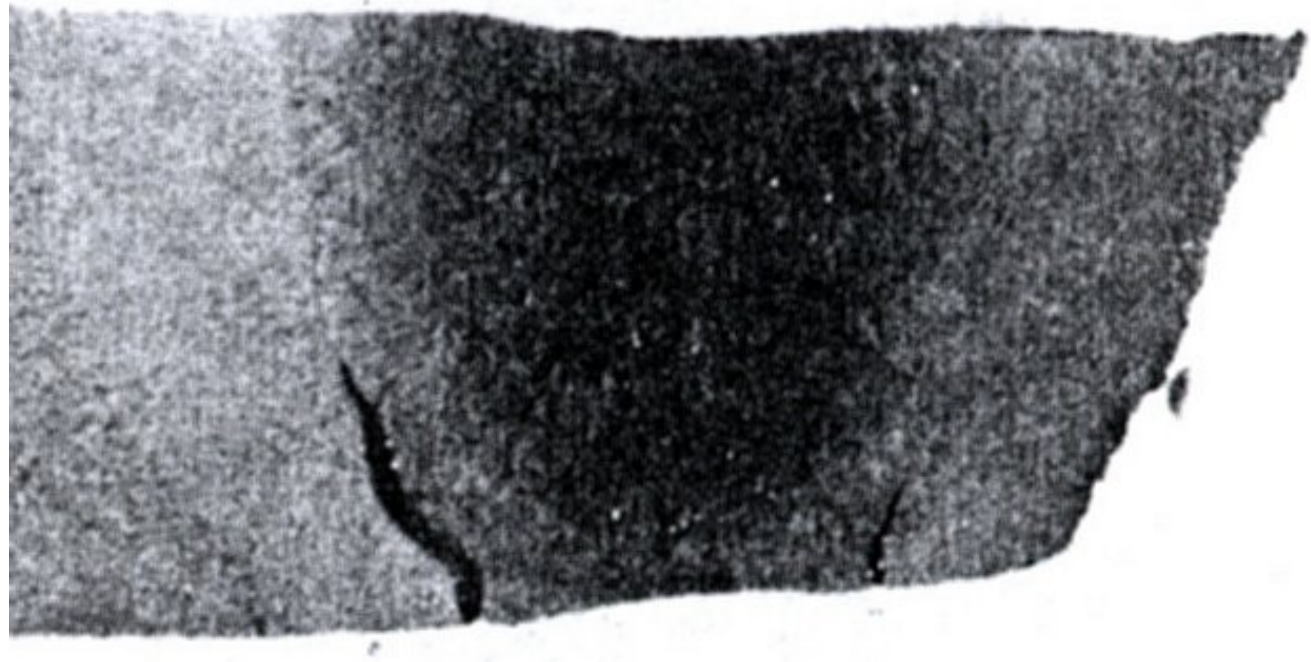

Figure 11: Comparison of predicted damage fields close to failure $t / t_{r}=0.99$, for (a) plane strain uni-axially loaded cross-weld testpieces at $600^{\circ} \mathrm{C}$ at an average minimum cross-section stress of $69.5 \mathrm{MPa}(2737 \mathrm{hr})$, with (b) a micrograph taken from a failed testpiece $(3223 \mathrm{hr})$. Testpiece failure takes place in the Type IV region. 